\title{
BOGOTÁ, D.C. PRIMERA EXPERIENCIA DE RECUPERACIÓN DE LA PLUSVALÍA URBANA PARA LA COLECTIVIDAD, EN EL MARCO DE LA LEY DE DESARROLLO TERRITORIAL. ${ }^{1}$
}

\author{
María Clara Vejarano \\ Departamento de Urbanismo. \\ Escuela de Arquitectura y Urbanismo. \\ Universidad Nacional de Colombia.
}

Remisión artículo: 17-07-2007

Palabras Clave: contribución de valorización, captura de plusvalías, Ley 388 de 1997.

Resumen: En América Latina, Colombia tiene reconocimiento en los medios académicos y de la administración pública relacionada con la financiación del desarrollo urbano, como un país que posee una experiencia importante en el empleo de la contribución de valorización ${ }^{2}{ }^{3}$. Mediante este instrumento se recuperan parte de los incrementos en el precio del suelo derivados de la ejecución de obras públicas por parte del Estado. Es decir, actúa parcialmente como un instrumento de recuperación de plusvalías, aunque tiene un límite de cobro, establecido por el costo de la obra, que impide que la recuperación tenga como referente el mayor valor adquirido por el suelo ${ }^{4}$.

El presente artículo informa acerca de la experiencia de la ciudad de Bogotá, entre los años 2000 a 2004, en la aplicación de un instrumento diferenciado, pero complementario de la contribución de valorización, denominado participación en la plusvalía. El objetivo explícito de este instrumento es recuperar entre el $30 \%$ y el $50 \%$ de la plusvalía generada por acciones del Estado, ya no solo circunscritas a la ejecución de obras públicas, sino debidas a acciones urbanísticas de las entidades públicas.

Las acciones urbanísticas a partir de las cuales la Ley de Desarrollo Territorial ${ }^{5}$ (388 de 1997) autoriza la recuperación de la plusvalía mediante este instrumento son las siguientes: i) la incorporación de suelo rural a suelo de expansión urbana o la consideración de parte del suelo rural como suburbano; ii) la autorización de un cambio de uso, a uno más rentable, y iii) la autorización de un mayor aprovechamiento del suelo en edificación. Todas las anteriores decisiones constituyen acciones administrativas de las entidades públicas, en las que aun cuando no está comprometida la inversión de recursos económicos por parte de ellas, en ejercicio de sus funciones en materia de urbanismo, generan un incremento en los precios del suelo, el cual no obedece a un esfuerzo del propietario del mismo ${ }^{678}$.

\footnotetext{
Este artículo constituye una adaptación y versión reducida, del artículo con el mismo nombre contenido en "Movilización social de la valorización de la tierra: casos latinoamericanos". Vejarano, María Clara compiladora editora. Lincoln Institute of Land Policy Cambridge, Massachussets. 2007 CD Rom. La versión del artículo contenido en el CD Rom fue elaborada conjuntamente por Sandra Viviana Salgado Naranjo, Alexander Sierra Leguizamón, Magda Cristina Montaña y María Clara Vejarano.

2 En otros paises de América Latina se denomina Contribución por mejoras.

3 Vejarano, María Clara. Contribución de valorización. La experiencia de Bogotá durante la década de los 80 y 90. Lincoln Institute of Land Policy. Sin publicar

${ }^{4}$ Jaramillo, Samuel. La experiencia colombiana en la recuperación estatal de los incrementos del precio del suelo. La Contribución de Valorización y la Participación en Plusvalías. En: "Recuperación de plusvalías en América Latina, alternativas para el desarrollo urbano". Smolka, Martim y Furtado, Fernanda, editores. Pontifica Universidad Católica de Chile, Eurelibros, Lincoln Institute of Land Policy, 2001.

${ }^{5}$ El texto de la Ley puede consultarse en www.minambiente.gov.co, en el enlace Normatividad.

6 Jaramillo, Samuel. Consideraciones teóricas sobre la participación de los municipios en las plusvalías urbanas. En: "Desarrollo urbano en cifras". Bogotá - Colombia No.4, mayo 1998. Viceministerio de Vivienda, Desarrollo Urbano y Agua Potable - Cenac.
} 
La participación en la plusvalía fue consignada en el artículo 82 de la Constitución Política de Colombia de 1991 como un Derecho Colectivo y del Ambiente. En 1997, la Ley de Desarrollo Territorial (LDT), en uno de sus catorce capítulos ${ }^{9}$, definió e hizo precisiones conceptuales y operativas sobre la aplicación del instrumento.

Sin embargo, sólo hasta finales del año 2003, Bogotá adoptó de manera específica este tributo mediante el Acuerdo "Por el cual se establecen las normas para la aplicación de la participación en plusvalías en Bogotá, Distrito Capital" (Acuerdo 118 de 30 de diciembre de 2003) y, por mandato de este Acuerdo, inició su aplicación al año siguiente.

El artículo informa sobre dos períodos de tiempo, el primero entre 2000 y 2002 y el segundo entre mediados de 2003 y el primer semestre de 2004, en los que la Administración Distrital inició y dio continuidad a la discusión sobre la adopción de la participación en la plusvalía. Como resultado de este proceso, durante los meses de enero a abril de 2004 y después de un desarrollo técnico, conceptual y jurídico que puede calificarse como pionero, desarrollado por la Administración de la ciudad, fue posible por primera vez en el país, calcular, liquidar, aplicar la tarifa y notificar la obligación de pagar la plusvalía, a los propietarios de aproximadamente 5.575 inmuebles en los que se había configurado el efecto plusvalía, como efecto de la aplicación de las normas del Plan de Ordenamiento Territorial (POT) de la ciudad.

A partir de esta primera experiencia, la administración pública de Bogotá ha ido involucrando -no sin dificultades- el proceso de aplicación de la participación en la plusvalía como parte de sus actividades rutinarias y hasta el mes de marzo de 2008, el recaudo es del orden de aproximadamente $\$ 33.937$ millones de pesos equivalentes a US $\$ 19.216 .000^{10}$.

De esta experiencia interesa resaltar la manera como se superaron los diversos y aparentes obstáculos que los opositores a la aplicación de la participación en la plusvalía argumentaban como dificultades, en algunos casos insalvables o cuya única resolución -a su juicio- residía en la modificación de la Ley, es decir, en su paso nuevamente por el Congreso de la República.

La alternativa de modificar la Ley hubiera sido un proceso muy complejo y entrañaba un peligroso riesgo de que fueran derogados o modificados los componentes esenciales de la Ley, la cual debe considerarse como una Ley del Suelo progresista, que define el ordenamiento del territorio como una función pública y que establece como principios del ordenamiento territorial en Colombia, la función social y ecológica de la propiedad, la prevalencia del interés general sobre el particular y, la distribución equitativa de las cargas y los beneficios derivados del ordenamiento urbano.

El artículo describe la forma como, a partir de varias circunstancias favorables, fue posible superar los argumentos que eran contrarios a la posibilidad de dar aplicación a este tributo y desarrollar todos los procedimientos técnicos requeridos para calcular, liquidar, aplicar la tarifa y notificar la obligación de pagar la plusvalía a los propietarios de aproximadamente 5.575 inmuebles, en un tiempo récord de tres meses.

En la primera sección del artículo se presenta información general sobre la Ley de Desarrollo Territorial, en particular sobre el capítulo IX, Participación en plusvalía, que desarrolla los aspectos operativos, desde el cálculo hasta el cobro, destino de los recursos, formas de pago y otros procedimientos.

\footnotetext{
7 García Bellido, Javier. Perspectivas del nuevo urbanismo colombiano: un análisis de su estructura. En: "Desarrollo Urbano en cifras". Bogotá - Colombia No. 5, agosto 1998. Viceministerio de Vivienda, Desarrollo Urbano y Agua Potable - Cenac.

8 Smolka, Martim y Furtado, Fernanda. Ensayo introductorio: Recuperación de plusvalías en Latinoamérica: ¿bravura o bravata?. En: "Recuperación de plusvalías en América Latina, alternativas para el desarrollo urbano. Smolka, Martim y Furtado, Fernanda, editores. Pontificia Universidad Católica de Chile, Eurelibros, Lincoln Institute of Land Policy. 2001

${ }^{9}$ Participación en la plusvalía: Ley 388 de 1997, capítulo IX, artículos 73 a 90.

$101 \mathrm{US} \$=\$ 1766$, cambio de dólares a pesos de 30 mayo de 2008
} 
La segunda sección describe, específicamente para Bogotá, aspectos más directamente relacionados con la aplicación de la plusvalía: i) el contenido general del Plan de Ordenamiento Territorial, herramienta de planeación en la que se originan los hechos generadores de plusvalía; ii) las discusiones que se desarrollaron dentro de la Administración Distrital en relación con la elaboración del Proyecto de Acuerdo de Adopción de la Plusvalía y las dificultades que se consideraba no hacían viable la aplicación del instrumento; iii) la presentación al Concejo de la ciudad de dos proyectos de acuerdo de reforma tributaria, dentro de los cuales se incluía la participación en la plusvalía, y iv) la reglamentación o desarrollo con mayor nivel de detalle de las normas generales del POT, en las que se precisaron e hicieron cuantificables los hechos generadores de la plusvalía.

La tercera sección presenta el contenido del Acuerdo 118 de 2003, por medio del cual se adopta en Bogotá la participación en la plusvalía. En la cuarta sección se describe el procedimiento que adelantaron las tres entidades distritales que por sus funciones están directamente involucradas con el tema de la plusvalía ${ }^{11}$, para poner en marcha el tributo entre enero y abril de 2004. En la última sección, se plantean algunas conclusiones de este proceso, que tienen como objetivo, subrayar y resaltar la importancia que tuvo, en el caso de Bogotá, la confluencia de la decisión política del Alcalde de la ciudad, la sólida argumentación teórica y jurídica, con la decisión y diligencia para superar dificultades técnicas.

\section{La ley de desarrollo territorial.}

En 1997, el Congreso de la República aprobó la Ley de Desarrollo Territorial (LDT o Ley 388/97), que debe ser considerada como una ley de urbanismo y suelo, equivalente a la importancia que tiene en Brasil el Estatuto de la Ciudad. Con esta Ley finaliza un período de casi 40 años de múltiples intentos legislativos promovidos por representantes de partidos políticos de ideologías opuestas, interesados en que se diera cumplimiento al concepto de propiedad establecido en la Reforma Constitucional y Política de 1936 ("la propiedad es una función social" ${ }^{12}$ ) y en que se aprobara una Ley que desarrollara y definiera instrumentos y procedimientos prácticos para regular el mercado del suelo urbano y periurbano. A lo largo de estos 40 años, de los aproximadamente 15 proyectos de ley presentados al Congreso, solamente uno se convertiría en Ley con anterioridad a la Ley de Desarrollo Territorial: la Ley de Reforma Urbana de 1989. Todos los demás intentos fueron sistemáticamente rechazados e impedida su aprobación.

La Ley de Reforma Urbana o Ley 9a de 1989 estableció un conjunto de nuevos instrumentos que contribuyen de diversa manera a regular el mercado del suelo: declaratoria de interés público, reajuste de tierras e integración inmobiliaria, expropiación -ya existente para ese momento en la legislación colombiana-, banco de tierras, derecho de preferencia, declaratoria de desarrollo y construcción prioritarios, y participación en la plusvalía. A esta última se le dio el nombre de contribución de desarrollo municipal. Su aplicación no pudo siquiera intentarse, pues fue declarada inexequible por una de las cortes, debido a un error en el procedimiento mediante el cual se incluyeron, en el texto del proyecto de ley, algunas exenciones al pago de esta contribución.

La Ley de Desarrollo Territorial, aprobada ocho años después de la Reforma Urbana, es también una ley que cuestiona la propiedad privada absoluta del suelo y se compromete con la

\footnotetext{
11 Departamento Administrativo de Catastro Distrital, hoy Unidad Administrativa Especial de Catastro Distrital, Departamento Administrativo de Planeación Distrital, hoy Secretaría Distrital de Planeación y, Secretaría Distrital de Hacienda.

${ }_{12}$ Maldonado, María Mercedes. La propiedad en la Constitución colombiana de 1991. Superando la tradición del código civil. Versión ajustada para el Curso profesional de recuperación en plusvalías en América Latina, Lincoln Institute of Land Policy, Septiembre 2003 y 2004, de la publicada en Arocha, Jaime., compilador. 2004. Utopía para los excluidos. El multiculturalismo en África y América Latina. Bogotá: Universidad Nacional de Colombia, Facultad de Ciencias Humanas, Centro de Estudios Sociales CES, pp. 347-363.
} 
regulación pública del mercado del suelo. Desde un punto de vista político y técnico, implica un avance en relación con la Ley de Reforma Urbana, por cuanto define unos fundamentos para el ordenamiento urbano en Colombia y establece una relación directa y operativa entre instrumentos de planeamiento urbano e instrumentos de regulación pública del mercado del suelo ${ }^{13}$.

En la Ley de Reforma Urbana, a pesar de que quedaron consignados los instrumentos de gestión pública del suelo ya mencionados, se mantuvo intacto, por omisión, el contenido operativo predominante del urbanismo en Colombia. Esta práctica, en la que ha prevalecido una modalidad que podría llamarse "urbanismo inmobiliario", ha estado basada casi exclusivamente en la asignación en el suelo de uso privado, de usos del suelo y metros cuadrados de edificabilidad -asignación de rentas urbanas-, con exigencia de muy pocas contraprestaciones al propietario del suelo en materia de infraestructuras públicas, equipamientos colectivos y de redistribución de la plusvalía obtenida sin su esfuerzo. Aunque la inclusión de los instrumentos de regulación del mercado del suelo en esta Ley produjo efectos prácticos muy limitados, constituyó un importante avance político y propició posteriores discusiones e intentos de aplicación, que condujeron a la elaboración de la Ley de Desarrollo Territorial.

La Ley de Desarrollo Territorial define el ordenamiento del territorio como una función pública y establece como principios del ordenamiento territorial en Colombia, los siguientes:

1. la función social y ecológica de la propiedad

2. la prevalencia del interés general sobre el particular

3. la distribución equitativa de las cargas y los beneficios derivados del ordenamiento urbano La Ley establece procedimientos e instrumentos concretos de planeamiento urbano y de regulación del mercado del suelo que se integran entre sí de manera bastante precisa y coherente, ofreciendo una plataforma operativa muy completa para garantizar el cumplimiento de los fundamentos de la Ley ${ }^{14}$. Uno de estos instrumentos, la participación en la plusvalía, responde estrictamente al objetivo establecido en el artículo 82 de la Constitución Política: “... las entidades públicas participarán en la plusvalía que genere su acción urbanística y regularán la utilización del suelo y del espacio aéreo urbano en defensa del interés común".

\subsection{La participación en la plusvalía en la Ley de Desarrollo Territorial}

El capítulo IX de la LDT, Participación en la plusvalía, desarrolla de manera detallada tanto el concepto de plusvalía que deberá adoptarse en las ciudades colombianas, como el procedimiento operativo que deberá seguirse, desde el cálculo de la plusvalía hasta el pago de la misma a la Administración Municipal.

Algunos investigadores, académicos y funcionarios públicos consideran que la Ley se excedió en el establecimiento de procedimientos técnicos y plazos, condición que ha sido interpretada como una limitación a la autonomía municipal, y como un exceso de detalle que puede estar generando dificultades operativas y económicas para que algunos municipios pongan en marcha el instrumento.

\footnotetext{
${ }^{13}$ Esta asociación estrecha entre categorías específicas del urbanismo y la regulación pública del mercado del suelo, lamentablemente, no ha sido suficientemente valorada por los urbanistas colombianos, para quienes el reconocimiento de esta relación, parece implicar una claudicación del interés, muy válido, por defender la especificidad espacial del urbanismo. Una cosa no implica la otra.

${ }^{14}$ Un número importante de los instrumentos de regulación del mercado del suelo ya habían sido adoptados por la Ley de Reforma Urbana; no así, los relacionados con decisiones de ordenamiento urbano (planes parciales, unidades de actuación urbanística). Entre los instrumentos contenidos en esta Ley se mencionan algunos: i) Clasificación del suelo, con incidencia en la definición de la responsabilidad de la propiedad del suelo en la asunción de cargas urbanísticas, como requisito para acceder a los beneficios del ordenamiento urbano, representados en la asignación de usos y edificabilidad; ii) planes parciales y unidades de actuación urbanística, como instrumentos de planeamiento y gestión del suelo que posibilitan el reparto equitativo de las cargas y beneficios, en diferentes escalas de la ciudad -desde la escala general hasta escalas menores-; iii) reajuste de tierras; iv) expropiación; v) desarrollo y construcción prioritaria; vi) enajenación voluntaria, expropiación judicial y por vía administrativa; vii) participación en la plusvalía.
} 
El argumento contrario también es posible: de no haber quedado establecido un procedimiento tan preciso, la aplicación del tributo se hubiera dificultado, por ausencia de reglamentación. En el caso de Bogotá, la precisión del procedimiento establecido en la LDT contribuyó a racionalizar y organizar la puesta en marcha efectiva de la participación.

Entre los conceptos y procedimientos contenidos en la Ley se encuentran los siguientes:

- Noción (art. 73): Se define como plusvalía, de acuerdo con lo establecido en el artículo 82 de la Constitución Política, el beneficio económico derivado del incremento de aprovechamiento en la utilización del suelo y del espacio aéreo urbano, producido por las acciones urbanísticas de regulación que son competencia de las entidades públicas, lo cual les da derecho a éstas a participar de este beneficio ${ }^{15} 16.17$

Para que un municipio colombiano pueda dar aplicación efectiva a la participación en la plusvalía, no es suficiente su adopción en la Constitución como derecho colectivo, ni la definición y procedimientos para su cálculo y cobro establecidos en la LDT. Debido a las competencias territoriales que están establecidas en Colombia en materia de impuestos, cada municipio debe adoptar, mediante Acuerdo aprobado por el Concejo Municipal, las normas específicas para su aplicación en el respectivo territorio municipal.

- Hechos generadores (art. 74): Las decisiones de las entidades públicas municipales consideradas como generadoras del efecto plusvalía, en los términos establecidos por la Constitución y la LDT, y que deben ser adoptadas en el Plan de Ordenamiento Territorial de cada municipio, son tres: i) la incorporación de suelo rural a suelo de expansión urbana o a suelo suburbano, ii) la modificación de la zonificación de usos del suelo con autorización de usos más rentables respecto de los existentes y iii) la autorización de un mayor aprovechamiento del suelo en edificación.

Para cada uno de los hechos generadores, la Ley establece un procedimiento de cálculo del efecto plusvalía ${ }^{18}$. Consiste en la realización de dos avalúos comerciales para las zonas geoeconómicas homogéneas en las que se encuentran ubicados los predios beneficiados con el efecto plusvalía. El primer avalúo debe expresar el precio del suelo por metro cuadrado, determinado por la norma urbanística anterior a la generación del efecto plusvalía; es decir, según sea el caso, como suelo rural o suelo con uso menos rentable y/o aprovechamiento en edificación menor al que ha sido aprobado con la nueva norma urbanística.

El segundo avalúo debe expresar el precio que adquirirá el suelo por metro cuadrado, una vez que el inmueble respectivo haga uso de la nueva norma urbanística. La diferencia entre los dos avalúos del suelo por metro cuadrado, multiplicada por el área total del lote, constituye el efecto plusvalía tota ${ }^{19}$.

- Monto de la participación (art. 79): Se establece una tasa de participación a la Administración Municipal en la plusvalía generada de entre el 30\% y el 50\% del efecto plusvalía total; se deja a discreción del Concejo Municipal la adopción de la(s) tasa(s) que se aplicará(n) en cada municipio.

\footnotetext{
15 Smolka y Furtado, 2001

16 Jaramillo, 2001

17 García Bellido, 1998

${ }^{18}$ LDT, artículos 75 a 77 .

${ }^{19}$ Al lector de este texto le pueden surgir algunas preguntas acerca del tema de los dos avalúos: i) momento en que deben realizarse cada uno de los dos avalúos, ii) conversión de los avalúos a un mismo momento en el tiempo para hacer comparables los datos de precios del suelo, iii) aspectos metodológicos de la elaboración de los avalúos, iv) disponibilidad de información de precios del suelo para períodos anteriores al del momento de elaboración del primer avalúo, con el fin de eliminar incrementos del precios del suelo derivados del anuncio de la nueva norma, etc. Algunos de estos temas serán desarrollados con algún detalle más adelante en el texto.
} 
- Procedimiento de cálculo y liquidación del efecto plusvalía (arts. 80, 81): La Ley define un procedimiento y un cronograma, que deberán adoptar las administraciones municipales desde el momento en que se acoge la norma urbanística que empieza a configurar el hecho generador del efecto plusvalía, hasta que se notifica a los propietarios de los inmuebles y se informa a terceros.

Este procedimiento incluye:

i) la solicitud de cálculo del efecto plusvalía por parte del alcalde dentro de cinco días hábiles $^{20}$ después de adoptada la norma urbanística que constituye el hecho generador;

ii) las entidades a las que el alcalde puede solicitar la realización de los avalúos y por lo tanto el cálculo del efecto plusvalía (entidades catastrales nacional y locales, y avaluadores privados) y el plazo de tiempo que tienen para hacerlo (60 días hábiles como máximo);

iii) los plazos de que dispone el alcalde, una vez recibe de la entidad avaluadora la determinación del efecto plusvalía, para liquidar el efecto plusvalía, aplicar la tasa correspondiente a cada uno de los inmuebles, expedir el acto administrativo y notificarlo a los propietarios (45 días +30 días hábiles);

iv) los medios que se deben emplear para notificar a los propietarios (tres avisos en edición dominical de periódicos reconocidos en la ciudad y edicto fijado en la sede de la alcaldía);

v) la inscripción, en el folio de matrícula inmobiliaria de los inmuebles ${ }^{21}$, de la responsabilidad que tiene el propietario de pagar la participación en la plusvalía, como manera de informar sobre el gravamen a un posible comprador para que sea conciente de que asume la responsabilidad de pagar el tributo en caso de adquirir el inmueble.

- Revisión de la estimación del efecto plusvalía (art. 82): Los propietarios o poseedores de los inmuebles pueden solicitar que la Administración Municipal revise el efecto plusvalía estimado para la zona en la que se encuentra su predio y para que se haga un nuevo avalúo, para lo cual tienen cinco días hábiles después de la publicación del último de los tres avisos de periódico mediante los cuales se hace la notificación.

- Exigibilidad y cobro de la participación (art. 83): Se establecen cuatro situaciones en las que el propietario o poseedor del inmueble deberá demostrar haber hecho el pago de la participación:

i) solicitud de la licencia de urbanización o construcción, aplicable para los tres hechos generadores del efecto plusvalía ${ }^{22}$;

ii) cambio efectivo de uso del inmueble, aplicable para el caso de autorización a un uso más rentable;

iii) transferencia de dominio sobre el inmueble, aplicable al paso de suelo rural a de expansión urbana y a la autorización de un mayor aprovechamiento del suelo en edificación $n^{23}$;

iv) adquisición de títulos valores representativos de derechos adicionales de construcción y desarrollo, que es un instrumento alternativo para hacer efectiva la participación en la plusvalía.

\footnotetext{
${ }^{20}$ Día hábil hace referencia a los días entre lunes y viernes, sin tener en cuenta sábado, domingo y días festivos.

${ }_{21}^{21}$ Registro público nacional de la historia de la propiedad de cada inmueble.

${ }^{22}$ El Decreto 1788 de 2004 del Ministerio de Ambiente, Vivienda y Desarrollo Territorial modificó esta condición, haciendo exigible el pago de la participación en el momento de la expedición de la licencia y no en el de su solicitud, atendiendo al concepto jurídico que establece que el hecho generador de la plusvalía está constituido por la autorización específica para el nuevo uso y/o la mayor edificabilidad y no la norma general.

${ }^{23}$ Este momento de exigibilidad ha sido criticado, pues en el momento de la venta del inmueble no hay seguridad de que efectivamente el nuevo propietario vaya a hacer uso del beneficio normativo que constituye el hecho generador del efecto plusvalía. Es decir, se podría estar exigiendo el pago, aun antes de obtener el beneficio. Bogotá no adoptó esta situación como momento de exigibilidad del pago.
} 
- Formas de pago (art. 84): Se establecen cinco posibles formas de pago, en las que siempre deberá haber una equivalencia con la obligación en dinero que ha sido liquidada y notificada a cada propietario o poseedor:

i) dinero en efectivo;

ii) porción de terreno, que puede ser parte del predio que genera la plusvalía o estar localizado en otra área de la ciudad, manteniendo siempre la equivalencia del valor correspondiente al pago de la participación;

iii) admitiendo como socio del proyecto inmobiliario a la administración municipal, mediante el reconocimiento a ésta de un valor accionario equivalente al pago de la participación;

iv) construcción de obras de infraestructura vial, de servicios públicos y/o de equipamientos sociales en zonas de la ciudad de desarrollo incompleto;

v) adquisición anticipada de títulos valores representativos de la participación en la plusvalía.

- Destinación de los recursos (art. 85): Los recursos provenientes del pago de la participación en la plusvalía se pueden destinar a las siguientes acciones:

i) planes y proyectos de vivienda de interés social;

ii) adecuación y mejoramiento de barrios incompletos: infraestructura vial, servicios públicos domiciliarios, parques y equipamientos sociales;

iii) red de espacio público: obras de recreación, parques, zonas verdes, equipamientos;

iv) infraestructura vial y sistemas de transporte masivo de interés general;

v) programas de renovación urbana;

vi) fomento de la creación cultural y del patrimonio cultural, especialmente en zonas de la ciudad de desarrollo incompleto.

- Independencia de otros gravámenes y participación en la plusvalía por ejecución de obras públicas (arts. 86 y 87): Se establece que la participación en la plusvalía es independiente de otros gravámenes, que podrá utilizarse la participación para recuperar el incremento en el precio del suelo debido a la construcción de obras públicas, siempre y cuando no se haya utilizado la contribución de valorización..

Las anteriores precisiones constituyen, de manera general, el contenido de la Ley de Desarrollo Territorial en relación con la participación en la plusvalía.

\section{El plan de ordenamiento territorial de Bogotá}

La LDT estableció la obligatoriedad de elaborar un Plan de Ordenamiento Territorial (POT) a todos los municipios con una población superior a 100.000 habitantes ${ }^{24}$. Este Plan está definido en la Ley como un instrumento de planeamiento de carácter marcadamente territorial: "...conjunto de objetivos, directrices, políticas, estrategias, metas, programas, actuaciones y normas adoptadas para orientar y administrar el desarrollo físico del territorio y la utilización del suelo".

La estrecha articulación que establece la Ley entre principios del ordenamiento territorial, instrumentos de planeamiento urbanístico e instrumentos de regulación pública del mercado del suelo constituyen la esencia de los planteamientos de la Ley y su principal aporte e innovación.

Quedó establecido un marco normativo, que impone la superación de la tradición más influyente en el urbanismo colombiano, que debe ser llamada sin eufemismos "urbanismo

\footnotetext{
${ }^{24}$ La Ley estableció otras dos categorías de planes para municipios con un número menor de habitantes: i) Planes básicos de ordenamiento territorial, para municipios de entre 30.000 y 100.000 habitantes y ii) Esquemas de ordenamiento territorial para municipios con población inferior a 30.000 habitantes.
} 
inmobiliario" ${ }^{25}$, practicado en Colombia durante todo el siglo XX, particularmente a partir de los años cincuenta, cuando se desarrolló el más intenso y dinámico proceso de urbanización del país. Esta tradición constituyó la fuente de la que aprendieron buena parte de los practicantes de esta disciplina, representados tanto por los funcionarios públicos como por los profesionales liberales, los propietarios del suelo, los miembros del gremio inmobiliario e incluso una proporción importante de los docentes universitarios en el área del urbanismo.

La LDT obliga a la modificación y renovación de las ideas y procedimientos operativos en relación con el ordenamiento del territorio urbano, en función de prácticas orientadas no solamente hacia la mejor calidad y equipamiento general del espacio urbano, sino inequívocamente comprometidas con procesos de mayor equidad, inclusión social y sostenibilidad ambiental. No obstante, el proceso de cambio, aunque efectivamente está sucediendo, es lento y subsisten prácticas inadecuadas e insuficientes que se derivan de diversas formas de resistencia a los principios establecidos en la Ley.

A partir del caso de Bogotá se ejemplificarán algunos de estos avances e interpretaciones equívocas.

\subsection{Primer Plan de Ordenamiento Territorial para Bogotá ${ }^{26}$ - Decreto 619 de $2000^{27}$}

Aspectos generales ${ }^{28}$ : El Plan de Ordenamiento de Bogotá merece ser estudiado y analizado para evaluar el contenido de algunos de los intereses que manifestaron las administraciones municipales del país en la adopción de los principios de la LDT, entre los que fue inevitable una actitud ambigua en relación con la regulación pública del mercado del suelo, actitud característica del inicio de este proceso.

EI POT de Bogotá adoptó de manera explícita varias de las exigencias que la LDT estableció para estos planes y fijó planteamientos específicamente urbanísticos, con la pretensión e interés de definir un modelo de ciudad, categoría urbanística a cuya ausencia en procesos anteriores de planeamiento de la ciudad se ha asignado la responsabilidad del fracaso del planeamiento urbano en Bogotá ${ }^{29}$

i) Clasificó el suelo del Distrito en suelo urbano, de expansión y rural, y dentro de ellos especificó el suelo de protección, estrecha aunque no exclusivamente representado por el suelo que en este plan se denominó estructura ecológica principal.

\footnotetext{
${ }^{25}$ Práctica que de manera general se caracteriza por: i) la protección implícita y explícita del derecho absoluto de propiedad, ii) la presencia de algunas de las expresiones de este concepto, como la entrega gratuita a los propietarios del suelo, de las plusvalías producidas por la acción del Estado, con todas las inequidades sociales y territoriales que genera esta práctica y, iii) la producción deficitaria y muy por debajo de los estándares requeridos, de la infraestructura urbana que hace parte esencial del proceso de urbanización: equipamientos educativos, recreativos, de salud, de cultura, de bienestar social, etc.

${ }^{26}$ Se trata del primer plan de ordenamiento para Bogotá elaborado con posterioridad a la expedición de la Ley de Desarrollo Territorial y no en sentido estricto, del primer proceso de planeación urbanística de la ciudad. Bogotá, en su condición de capital del país, es la ciudad colombiana que más tempranamente ejerció diversas modalidades de planeamiento urbano desde los años treinta del siglo XX que se expresaron en la producción y aprobación de una amplia normativa urbanística. Este Plan fue revisado en 2003 y la revisión fue adoptada mediante Decreto 469 de 2003. La recopilación de las normas de los Decretos 619 de 2000 y 469 de 2003 fue adoptada mediante Decreto 190 de 2004 , vigente en la actualidad.

${ }^{27}$ Debido a demoras en el trámite del Plan ante el Concejo de la ciudad, el POT de Bogotá fue adoptado mediante Decreto del alcalde de la ciudad, Enrique Peñalosa y no mediante Acuerdo del Concejo Distrital.

${ }^{28}$ Debe entenderse que esta descripción es una simplificación del contenido del POT y solamente señala los temas de mayor importancia para los efectos de este artículo.

${ }^{29}$ Esta consideración requiere un debate académico riguroso, pues ha sido progresivamente aceptada sin mayor cuestionamiento. Detrás de ella considero que subyace un razonamiento ingenuo: el poder inherente de un modelo urbano, como posibilidad de solución de los problemas de la ciudad, que distrae la atención sobre las causas esenciales del fracaso del planeamiento urbano. Èstas están estrechamente asociadas con la ausencia de políticas públicas de regulación del mercado del suelo y a la complacencia -por acción u omisión- de la Administración Pública y de la sociedad, con los intereses privados de la propiedad del suelo; dicho de otra manera, a la adopción de un modelo específico de ciudad: la ciudad especulativa o la ciudad mercancía.
} 
ii) Adoptó, bajo el concepto de modelo territorial, un conjunto de políticas y decisiones en relación con la región y los componentes urbano y rural del territorio.

iii) En el componente urbano, a partir de la delimitación de "piezas urbanas y centralidades" que constituyen el modelo urbano propuesto, adoptó políticas, decisiones, programas, proyectos y normas en materia de medio ambiente y recursos naturales, expansión urbana, vialidad y transporte, servicios públicos, equipamientos colectivos, espacio público, vivienda, patrimonio, renovación urbana, normas para usos del suelo y tratamientos urbanísticos.

Entre estas decisiones, algunas, como la definición de áreas clasificadas como suelo de expansión de la ciudad, empiezan a constituir hechos latentes generadores del efecto plusvalía, debido a que autorizan la incorporación de suelo rural al de expansión urbana. El POT establece que la incorporación concreta de este suelo a suelo de expansión se producirá solamente cuando se apruebe un plan parcial que especifique los usos del suelo, la edificabilidad y los requerimientos de infraestructuras públicas y equipamientos colectivos que deberán desarrollarse en ese suelo. Por lo tanto, sólo en el momento en que haya normas definidas, será posible y deberá hacerse el cálculo del efecto plusvalía.

Otras normas que constituirán hechos generadores del efecto plusvalía, como la autorización de usos más rentables o de un mayor aprovechamiento del suelo en edificación, en zonas de la ciudad ya consolidadas, no son especificadas en el POT; solamente se adoptarán después de la aprobación del Plan, cuando se desarrollen otros instrumentos de planeamiento de menor jerarquía que éste, como la reglamentación de las llamadas unidades de planeamiento zonal (UPZ):

iv) En el componente rural adoptó decisiones y normas en materia de áreas protegidas -en particular los cerros orientales-, asentamientos humanos, sistema vial, centros poblados rurales y régimen de usos.

v) En una sección del Plan adoptó lo que se denominó Instrumentos de Gestión Urbana (Título V). Allí, de manera desarticulada y con evidente incomprensión del comportamiento del mercado inmobiliario y por lo tanto de la necesaria integración y complementación entre ellos, de los instrumentos de gestión del suelo y, entre éstos y los instrumentos de planeamiento, incluyó indiscriminadamente instrumentos como a) la asignación, por medio de "fichas normativas", de usos del suelo y edificabilidad predio a predio en las UPZ, en una reproducción bastante fiel de la tradición del urbanismo inmobiliario practicado a lo largo de los últimos 50 años; b) los planes parciales y otras categorías de planes -maestros de equipamientos y servicios públicos, maestros de parques, de reordenamiento, de recuperación geomorfológica de canteras, de implantación, de regularización y manejo- ${ }^{30}$; c) algunos instrumentos de regulación pública del mercado del suelo a los que se dio el nombre de instrumentos de actuación urbanística: reajuste de tierras, cooperación entre partícipes, mezclados con otros remanentes del urbanismo inmobiliario, como la urbanización y la edificación aislada; d) los denominados instrumentos de financiación, entre los cuales se incluyó la participación en la plusvalía $^{31}{ }^{32}$, los fondos para el pago compensatorio de cesiones públicas para parques, parqueaderos y equipamientos, títulos representativos de derechos de construcción y desarrollo, y bonos y pagarés de reforma urbana ${ }^{33}$.

\footnotetext{
${ }^{30}$ Ninguna de estas categorías de planes se asoció de manera directa y precisa con el principio de reparto equitativo de cargas y beneficios derivados del ordenamiento urbano, ni con los instrumentos de gestión pública del suelo contenidos en la LDT.

${ }^{31}$ La consideración de la participación en plusvalía como instrumento de financiación, evidencia el concepto estrecho que ha habido respecto de este instrumento. Se le considera prioritariamente como una fuente de recursos, pero se ignora su potencial como regulador del mercado del suelo y por lo tanto, con una importante incidencia en el desarrollo urbanístico general de la ciudad.

${ }^{32}$ La mención de la participación en la plusvalía en el POT no reemplazaba la necesidad de la adopción legal de este tributo para la ciudad, que debía hacerse mediante Acuerdo del Concejo Distrital.

${ }^{33}$ Los bonos y pagarés de reforma urbana constituyen modalidades de endeudamiento de la Administración Municipal a partir de recursos privados, adoptados en la Ley de Reforma Urbana.
} 


\subsection{Las discusiones sobre la participación en la plusvalía ${ }^{34}$}

Después de adoptado el POT y entre 2000 y 2002, los intentos de adopción de la participación en la plusvalía en Bogotá D.C. no tuvieron mayores resultados. Cuatro entidades distritales tenían algún interés y responsabilidad en el tema y participaron en la discusión: i) el Departamento Administrativo de Planeación Distrital (DAPD) ${ }^{35}$, entidad responsable entre otras obligaciones del ordenamiento territorial de la ciudad; ii) la Secretaría de Hacienda Distrital (SHD), responsable del manejo de las finanzas públicas distritales; iii) Metrovivienda, empresa comercial e industrial del Distrito, responsable de promover la construcción de vivienda para la población de bajos ingresos, que en Colombia recibe el nombre de vivienda de interés social, y iv) el Departamento Administrativo de Catastro Distrital (DACD) ${ }^{36}$, cuya función principal es el mantenimiento actualizado del inventario físico, jurídico y económico de los bienes inmuebles del Distrito y la realización de los avalúos comerciales que requieran las entidades públicas.

Durante este período, el interés predominante de estas entidades, particularmente de las tres primeras -DAPD, SHD y Metrovivienda- en relación con la participación en la plusvalía, era de carácter financiero: interesaba adoptar el tributo como fuente de financiación de los proyectos adoptados por el POT; este interés para Metrovivienda era más específico: la financiación de vivienda de interés social.

Aún no se entendía ni discutía la participación en la plusvalía como un instrumento de regulación del mercado del suelo, que en asocio con los demás instrumentos que cumplen esta función y están establecidos en la ley ${ }^{37}$ tiene efectos concretos en el ejercicio del principio del reparto equitativo de las cargas y beneficios del desarrollo urbano en las diversas escalas de la ciudad. Tampoco se había asimilado aún la utilidad del conjunto de instrumentos para concretar los objetivos y proyectos del ordenamiento territorial, particularmente los relacionados con la adecuada presencia, en términos de localización y cantidad, de los usos y las actividades urbanas más frágiles, pero social y culturalmente esenciales, como las infraestructuras de servicios públicos, los sistemas de equipamientos de uso colectivo, la estructura ecológica y la sostenibilidad medioambiental y la vivienda para la población de bajos ingresos, entre otros.

Los obstáculos y discusiones en el período 2000-2002 se concentraron en los siguientes temas:

- Necesidad o no de adoptar la participación en la plusvalía mediante un acuerdo del Concejo Distrital: EI DAPD, a partir de un concepto jurídico contratado específicamente para este fin, argumentó que esta participación adoptada en una ley de ordenamiento territorial en la que no era descrita ni recibía el nombre de tributo, podía empezar a ser recaudada sin necesidad de su adopción por parte del Concejo Distrital.

La SHD discrepaba de este concepto, por cuanto tenía claridad de que la participación sí constituía un tributo y por lo tanto, en cumplimiento de la Constitución Política Nacional, debía ser el órgano de representación popular -Concejo Distrital- el que lo adoptara específicamente para Bogotá D.C. y estableciera los elementos mínimos para su aplicación. De hecho, durante

\footnotetext{
${ }^{34}$ Esta sección se redactó con base en el texto escrito para esta recopilación por la abogada Magda Cristina Montaña, en aquel momento subdirectora jurídico-tributaria de la Secretaría de Hacienda Distrital, y por los ingenieros catastrales Sandra Bibiana Salgado y Alexander Sierra, de la División de Actualización del Departamento Administrativo de Catastro Distrital.

${ }_{35}$ Hoy Secretaría Distrital de Planeación - SDP

36 Hoy Unidad Administrativa Especial de Catastro Distrital - UAECD

${ }^{37}$ Instrumentos hasta ese momento tampoco suficientemente entendidos y, por lo tanto, mencionados solamente de manera formal sin ningún efecto práctico: : i) Clasificación del suelo, con incidencia en la definición de la responsabilidad de la propiedad del suelo en la asunción de cargas urbanísticas, como requisito para acceder a los beneficios del ordenamiento urbano, representados en la asignación de usos y edificabilidad; ii) planes parciales y unidades de actuación urbanística, como instrumentos de planeamiento y gestión del suelo que posibilitan el reparto equitativo de las cargas y beneficios, en diferentes escalas de la ciudad, desde la escala general hasta escalas menores; iii) reajuste de tierras; iv) expropiación; v) desarrollo y construcción prioritaria; vi) enajenación voluntaria, expropiación judicial y por vía administrativa; vii) participación en la plusvalía.
} 
este período, la SHD presentó dos proyectos de acuerdo al Concejo Distrital, cuyo objetivo era una Reforma Tributaria Integral: "Tributar para Progresar", en la que se incluía la participación en la plusvalía.

- Imposibilidad de cobrar la participación, aun cuando se lograse su adopción por parte del Concejo Distrital, pues a la fecha en que se daban estas discusiones ya había sido aprobado el POT y, por lo tanto -era la discusión que se daba-, ya había ocurrido el hecho económico que hacía exigible la obligación tributaria. Por lo anterior y en cumplimiento del principio de irretroactividad para la aplicación de normas tributarias, la participación no podría ser exigida; el hecho económico que la generaba habría ocurrido con anterioridad a la hipotética aprobación del Acuerdo Distrital que la haría obligatoria para el Distrito ${ }^{38}$. Este argumento empezaba a ser de común utilización por parte no solamente de funcionarios del DAPD, sino de algunas otras ciudades del país.

- Aparente imposibilidad de calcular el efecto plusvalía para el hecho generador correspondiente a la autorización de un mayor aprovechamiento del suelo en edificación. El método de cálculo del efecto plusvalía establecido por la Ley para este hecho generador es equivocado (LDT, art. 77 y Decreto Reglamentario de la LDT 1599, art. 6), pues conduce a calcular un valor económico que involucra una relación entre el costo de construir los metros cuadrados adicionales autorizados y el área del terreno. Esta relación no tiene que ver estrictamente con la incidencia en el precio del suelo derivada de la autorización de un mayor potencial edificatorio o metros cuadrados adicionales de construcción.

Tanto el DAPD como la SHD consideraban en esa época que la única salida para esta dificultad estaba en manos del Gobierno Nacional, mediante la expedición de una norma reglamentaria de este nivel o una nueva ley -se preveía que podría ser el Proyecto de Ley de Ingresos Tributarios Territoriales- que precisara que la forma de cálculo del efecto plusvalía para este hecho generador solamente tuviera en cuenta la incidencia del potencial adicional de edificación en el precio del suelo ${ }^{39}$.

- Doble tributación, entre la participación en la plusvalía y, por un lado, el impuesto de propiedad, que es un tributo del orden municipal, $y$, por el otro, el de renta, perteneciente al nivel nacional ${ }^{40}$.

- El abundante número de avalúos necesarios para calcular el efecto plusvalía y el alto costo de su realización podría ser mayor que el recaudo de los recursos, resultando, por lo tanto, inocuo y aun contraproducente dar aplicación al tributo ${ }^{41}$.

- El prolongado proceso establecido por la Ley de Desarrollo Territorial entre la adopción de la norma que configura el hecho generador de plusvalía hasta su notificación a los propietarios de los inmuebles (mínimo siete meses), que daba lugar a que durante este tiempo los propietarios obtuvieran la licencia de urbanización y/o construcción, sin que hubieran sido notificados de su obligación del pago de la plusvalía, por tanto, haciendo imposible su cobro.

\footnotetext{
${ }^{38}$ Más adelante se explica la argumentación que se desarrolló para superar esta interpretación y posibilitar el cobro de la plusvalía para todos los hechos generadores establecidos en el POT - Decreto 619 de 2000, salvo en los casos en los que en el momento de su aplicación ya se hubiera expedido la licencia de urbanización y/o de construcción para el respectivo inmueble.

39 Mas adelante se explicará la forma como el Acuerdo de adopción de la participación en la plusvalía en Bogotá superó este obstáculo de procedimiento e incidió para que se adoptara la misma solución en un Decreto del nivel nacional, es decir, con aplicación para todo el país.

${ }^{40}$ Este argumento continuó teniendo mucha fuerza en las discusiones con la Asociación de Constructores, las lonjas de propiedad raíz, hasta la época de los debates del Proyecto de Acuerdo en el Concejo Distrital a finales de 2003.

${ }^{41}$ En el artículo se explicará que el uso de la metodología de zonas geoeconómicas homogéneas permite hacer avalúos para tan solo una muestra representativa de los predios que componen la zona homogénea y no para el universo completo de ésta. Así, se pudo desvirtuar el argumento de los altos costos derivados de la elaboración de los avalúos.
} 


\subsection{Primeros intentos de adopción de la participación en plusvalía en Bogotá}

A pesar de que en relación con la adopción de la participación en la plusvalía, el período entre 2000 y 2002 se caracterizó más por la confusión, las dudas y un ambiente general de escepticismo sobre las posibilidades de su aplicación, la SHD y el DAPD participaron en iniciativas tanto específicas de Bogotá como del Gobierno Nacional, orientadas a dar solución a algunos de los inconvenientes ya mencionados.

Durante 2001, la SHD elaboró dos proyectos de acuerdo para su discusión y aprobación en el Concejo Distrital, cuyo objetivo era establecer una reforma tributaria, "Tributar para Progresar", dentro de la cual se incluyó la participación en la plusvalía. Debido a la falta de madurez y de claridad en relación con la conceptualización sobre la participación, ninguno de los dos proyectos de acuerdo desarrolló alternativas a los obstáculos ya mencionados y se limitaron a hacer una transcripción casi textual del contenido de la LDT, con algunas precisiones de carácter operativo y de procedimientos: i) el establecimiento del 50\% como única tarifa de cobro, ii) la exención para la vivienda de interés social ${ }^{42}$, iii) la obligatoriedad por parte de los propietarios de los inmuebles beneficiados de presentar la liquidación del tributo ${ }^{43}$, iv) el señalamiento de sanciones por la no declaración del tributo por parte de los contribuyentes, v) reglas de procedimiento para la forma de pago mediante acciones asignadas a la Administración Distrital en proyectos inmobiliarios y vi) la destinación específica del recaudo dentro de los parámetros de la LDT.

Para ese momento, la Administración Distrital requería que el Concejo Distrital aprobara las iniciativas de la Reforma Tributaria que le representaran un volumen importante de recursos e inmediatez en la obtención de los mismos, condiciones que no cumplía la participación en la plusvalía. Así, lo que la SHD obtuvo de esta reforma fue, entre otras medidas, el incremento y mejoramiento del recaudo del impuesto de industria y comercio, el mejoramiento del régimen de procedimientos de los impuestos y de sanciones por no pago y la simplificación de beneficios en los impuestos predial y de vehículos. La participación en la plusvalía dejó de presentarse como un tema prioritario para la Reforma Tributaria, debido a la proyección un poco difusa del posible recaudo, a las críticas que surgieron a las normas del POT y a lo extenso del plazo para obtener el recaudo pleno.

Para este mismo período 2000-2002, tanto la SHD como el DAPD participaron en grupos de trabajo con la Dirección de Vivienda, Desarrollo Urbano y Agua Potable del Ministerio de Desarrollo Económico (trasladada después al Ministerio de Ambiente, Vivienda y Desarrollo Territorial) en la elaboración de un decreto reglamentario de la LDT en materia de participación en la plusvalía, y con el Ministerio de Hacienda, en un Proyecto de Estatuto de Ingresos Tributarios Territoriales. En los dos casos y cada uno en su especificidad -territorial urbanística y tributaria-, las propuestas desarrollaban y especificaban procedimientos operativos, sin asumir lo que se consideraba obstáculos importantes para la aplicación del tributo ${ }^{44}$, con excepción de la forma de cálculo del efecto plusvalía por mayor aprovechamiento del suelo en edificación. En ese período, finalmente no se avanzó en materia de reglamentación de la participación, ni en el nivel nacional ni distrital de Gobierno y se mantuvieron los equívocos acerca de su aplicación.

\footnotetext{
${ }^{42}$ En ese momento todavía era común el entendimiento equivocado de que la recuperación de la plusvalía por parte de la Administración Pública implica su traslado al comprador final del inmueble, con una directa incidencia en el encarecimiento del inmueble. De esta interpretación errónea se derivan las frecuentes iniciativas de ese momento, de establecer exenciones o tarifas diferenciales para la vivienda de interés social y otras situaciones consideradas estratégicas y que requieren incentivos, como por ejemplo, los programas de renovación urbana.

${ }^{43}$ Este es un procedimiento utilizado con otros tributos en la ciudad, que consiste en que a partir de unos montos de referencia que constituyen la obligación tributaria y son establecidos por la Secretaría de Hacienda, los contribuyentes liquidan y efectúan el pago correspondiente.

${ }^{44}$ En este artículo se presenta mas adelante la información que evidencia que Bogotá logró resolver los considerados obstáculos que requerían una modificación de la ley, mediante el Acuerdo finalmente aprobado por el Concejo Distrital en diciembre de 2003, a partir de una rigurosa conceptualización del tributo y sin hacer ninguna modificación a la Ley.
} 


\subsection{La reglamentación del Plan de Ordenamiento Territorial - Decreto 619 de 2000}

Una vez aprobado el POT y de manera simultánea a las discusiones que se acaban de mencionar en relación con la participación en la plusvalía, el DAPD inició el proceso de desarrollo y reglamentación del Plan de Ordenamiento. El área urbana y el suelo de expansión de Bogotá ocupan aproximadamente 40.000 hectáreas $\left(400 \mathrm{~km}^{2}\right)$, extensión que debido a la complejidad y número de decisiones que se deben tomar en desarrollo de un plan de ordenamiento, obligó a que el POT de Bogotá y de otras ciudades grandes y de escala intermedia, desarrollaran diferentes escalas territoriales de planeación y niveles progresivos de detalle y especificación de decisiones urbanísticas.

Las directrices territoriales estructurantes en la escala general de la ciudad fueron planteadas y desarrolladas en el documento del POT, adoptado mediante el Decreto 619 de $2000^{45}$. Como se mencionó en este documento, el POT tomó decisiones en materia de: i) clasificación del suelo en rural, de expansión y urbano, con la subcategoría de suelo de protección en cada uno de estos suelos; ii) políticas en relación con la región y los componentes urbano y rural del territorio; iii) modelo urbano, mediante la delimitación de "piezas urbanas y centralidades", territorios en los que de manera general se adoptaron políticas, decisiones, programas, proyectos y normas en materia de medio ambiente y recursos naturales, expansión urbana, vialidad y transporte, servicios públicos, equipamientos colectivos, espacio público, vivienda, patrimonio, renovación urbana, normas para usos del suelo y tratamientos urbanísticos.

En estricto sentido, ninguna de las decisiones estructurantes contenidas en el POT y adoptadas en el Decreto constituyó un hecho generador de plusvalía acabado y completo. La designación de suelo rural como suelo de expansión o la delimitación y asignación general de usos del suelo más rentables para ciertas zonas de la ciudad constituían solamente una posibilidad de incrementos en el precio del suelo respectivo. Estas decisiones adoptadas con un amplio nivel de generalidad no permitían a la Administración de la ciudad calcular el mayor precio del suelo, ni a los propietarios de éste hacer uso de la norma hasta tanto no hubiera una mayor especificación del aprovechamiento posible, mediante la reglamentación de las unidades de planeación zonal (UPZ) o el diseño detallado de los planes parciales y, en ambos casos, su adopción mediante decreto de la Alcaldía y el DAPD ${ }^{46}$.

Es decir, la normativa de la UPZ y los planes parciales constituyen una norma urbanística de carácter más específico, pues definen con precisión, para conjuntos de inmuebles agrupados en "sectores normativos", usos del suelo e indicadores de edificabilidad que permiten hacer el cálculo del efecto plusvalía en caso de que éste se presente. Mediante estas normas de mayor detalle se continúa configurando el hecho generador de la plusvalía, aun cuando la obligación tributaria solamente se produce mediante el otorgamiento de la licencia de urbanización o de construcción o autorización específica.

Durante el segundo semestre de 2000, el DAPD inició la reglamentación urbanística de las UPZ; también empezó a trabajar en los planes parciales, pero debido a que constituía una figura de planeación inédita, que exigía nuevos conocimientos para su diseño y gestión, como

\footnotetext{
${ }^{45}$ Se hace referencia a las decisiones estructurantes de lo que se puede llamar el Modelo Urbano para Bogotá, es decir, en términos territoriales o físico-espaciales. Sin embargo, como se mencionó, el POT presentaba una debilidad muy importante en materia de instrumentos de gestión pública del suelo, que debe ser considerada una falla estructural del Plan, en la medida en que esta ausencia se convierte en un obstáculo central para el logro del modelo urbano propuesto.

${ }^{46}$ Este planteamiento, desarrollado desde un punto de vista técnico y jurídico de manera más rigurosa, fue uno de los argumentos que respaldó la presentación y aprobación del Acuerdo de Plusvalía en Bogotá. Con él se refutó el concepto dominante hasta ese momento, tanto en la Administración Distrital como en el Gobierno Nacional, acerca de que el POT ya había definido los hechos generadores de plusvalía y que al no disponer del Acuerdo de Adopción del tributo con anterioridad o al mismo tiempo de la aprobación del POT, su cobro constituía un cobro retroactivo, no autorizado por la legislación tributaria.
} 
la técnica del reparto equitativo de cargas y beneficios del ordenamiento urbano, su desarrollo empezó a dilatarse. Para el momento de aprobación del Acuerdo de Adopción de la Plusvalía en Bogotá, en diciembre de 2003, solamente se habían aprobado once planes parciales, mientras que ya se habían reglamentado aproximadamente $16 \mathrm{UPZ}^{47}$. (ver figura 1 )

\section{Figura 1}

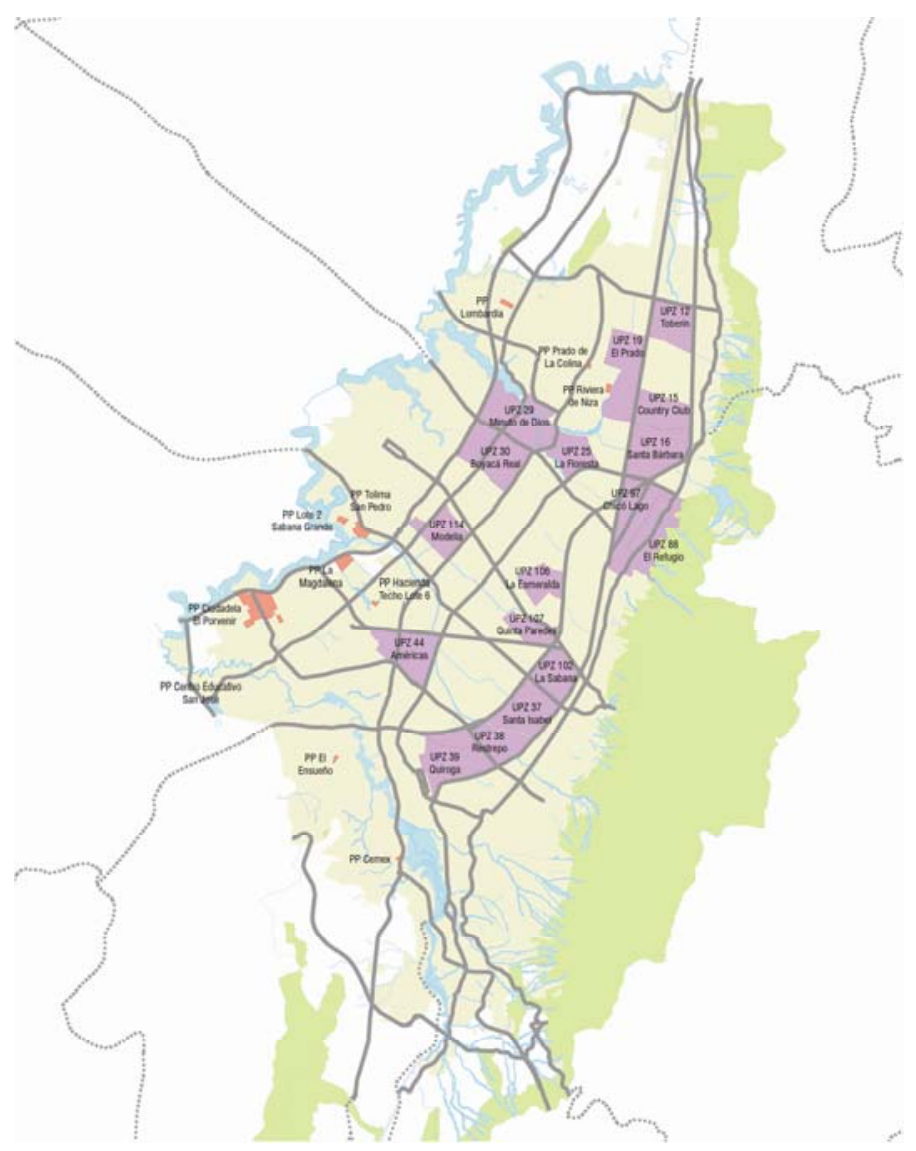

Las unidades de planeación zonal constituyen porciones del territorio de la ciudad ya construida y consolidada, con origen o no en la urbanización formal, “... conformadas por un barrio o conjunto de barrios tanto en suelo urbano como en suelo de expansión, que mantienen unidad morfológica y funcional". El área urbana de la ciudad fue dividida en 112 UPZ, que pueden tener en promedio una superficie de 350 hectáreas. El Plan de Ordenamiento Zonal es el instrumento definido por el POT para precisar las normas urbanísticas de las UPZ ${ }^{48}$.

En esencia, la reglamentación urbanística de las UPZ, si bien tuvo la pretensión de constituir un Plan, con precisión de su estructura urbana y de programas, además de la normativa de usos y edificabilidad, terminó siendo esto último, una norma de usos y edificabilidad que aplica a cada uno de los predios de la UPZ, agrupados en sectores normativos, caracterizados por una cierta homogeneidad urbanística y de usos del suelo, para los que se adoptan, mediante "fichas normativas", decisiones precisas en materia de:

\footnotetext{
${ }^{47}$ En 13 de estas 16 UPZ y en algunos sectores de las mismas, las normas de usos y edificabilidad aprobadas constituían de manera preliminar hechos generadores de plusvalía (después se constataría que en algunos sectores no se producía tal efecto). El número aproximado de predios pertenecientes a esos sectores de las 13 UPZ era de 18.000, que correspondían al $1 \%$ del total de predios de la ciudad.

${ }^{48}$ Este es el concepto sobre planes de ordenamiento zonal en el Decreto 619 de 2000. El Decreto mediante el cual se revisó el POT, al cual se hará referencia más adelante, modifica la definición de Plan de Ordenamiento Zonal.
} 
... normas que regulen el uso principal, los usos complementarios y los restringidos establecidos para el sector, la intensidad y mezcla de los usos específicos, los criterios para la localización de los usos, las exigencias de estacionamientos, las condiciones de edificabilidad con base en la aplicación de índices de ocupación y construcción, las alturas y aislamientos, las pautas para la determinación de los elementos relacionados con el espacio público tales como antejardines, paramentos, rampas y escaleras, y las demás normas necesarias para complementar el planeamiento de la zona específica... ${ }^{49}$.

De manera adicional a los anteriores contenidos, el Decreto mediante el cual se adopta la reglamentación de una UPZ incluye un capítulo de Instrumentos de Gestión Urbanística, uno de los cuales es la participación en plusvalía, que se especifica en el caso de que las normas de usos y edificabilidad adoptadas para cualquiera de los sectores normativos de la UPZ constituya un hecho generador de plusvalía.

A manera de ejemplo de la manera como se especifica la aplicación del efecto plusvalía en un decreto de reglamentación de UPZ, se transcribe el correspondiente a las UPZ 88/97 Refugio/Chicó Lago:

Artículo 15. APLICACIÓN DEL EFECTO PLUSVALÍA. De conformidad con lo dispuesto en los artículos 468 a 470 del Decreto Distrital 619 de 2000, son zonas con efecto plusvalía en las UPZ 88/97, REFUGIO/CHICÓ LAGO las siguientes:

\begin{tabular}{|l|l|}
\hline HECHO GENERADOR & SECTORES NORMATIVOS \\
\hline $\begin{array}{l}\text { 1. Por asignación de nuevas áreas } \\
\text { de actividad con cambio de uso a } \\
\text { uno más rentable: }\end{array}$ & $1,3,8,9,18$ \\
\hline $\begin{array}{l}\text { 2. Por asignación de nuevo } \\
\text { tratamiento con mayor edificabilidad: }\end{array}$ & $1,2,3,4,8,10,11,13,17$ y 18 \\
\hline
\end{tabular}

\section{Acuerdo 118 de 2003 "por el cual se establecen las normas para la aplicación de la participación en plusvalías en Bogotá, distrito capital" ${ }^{50}$}

Durante el segundo semestre de 2003, la Administración Distrital, con la asesoría del LILPLAC ${ }^{51}$, elaboró el Proyecto de Acuerdo de Adopción de la Participación en Plusvalía para su presentación al Concejo Distrital. El Acuerdo fue aprobado por esta corporación el 22 de diciembre del mismo año y sancionado por el alcalde de la ciudad Antanas Mockus Sivickas el 31 de diciembre.

A finales de 2002 se presentaron unas circunstancias favorables que aceleraron la adopción de la participación en la plusvalía en la ciudad. Hubo un importante acercamiento entre altos niveles de la Administración Distrital, representados en el Alcalde Mayor y el DAPD y el Programa del LILP en Colombia, concretamente de la persona responsable del mismo. En el DAPD se había producido recientemente un cambio en su Dirección; la nueva Directora manifestó un claro interés en la adopción de los instrumentos de regulación pública del mercado del suelo contenidos en la LDT, entre ellos la participación en la plusvalía.

Durante 2003, la Administración Distrital, con la asesoría técnica del LILP, preparó el Proyecto

\footnotetext{
${ }^{49}$ POT, Decreto 619 de 2000, artículo 453, Fichas Normativas.

${ }^{50}$ El análisis del proceso de elaboración y aprobación de este Acuerdo requiere una presentación específica para este fin, que no la constituye el presente artículo. Por lo tanto, en éste solamente se mencionarán los temas que constituyen la mayor contribución para el desarrollo práctico de la aplicación de la participación.

${ }^{51}$ Lincoln Institute of Land Policy - Programa para América Latina y el Caribe.
} 
de Acuerdo e hizo su presentación para discusión y aprobación en el Concejo Distrital, durante los meses de noviembre y diciembre de ese año.

Para las entidades participantes en la elaboración del Proyecto de Acuerdo, el DAPD y la SHD, ya había claridad en ese momento de que los obstáculos argumentados en el período 20002002 como impedimentos para dar aplicación al tributo -a los que se hizo referencia en la primera parte de este artículo ${ }^{52}$ - podían ser resueltos sin necesidad de acudir a una modificación de la LDT. La preparación del Proyecto de Acuerdo centró el énfasis en construir los argumentos conceptuales de contenido tributario y establecer el respaldo jurídico necesario, para dar adecuada salida a estos obstáculos.

La más importante contribución del Acuerdo de Plusvalías en Bogotá puede resumirse en los dos siguientes temas ${ }^{53}$ :

i) Desarrolló una argumentación acerca de que el hecho generador de la plusvalía es un proceso que puede llamarse "acto complejo", que no se configura en un solo momento en el tiempo, sino mediante decisiones sucesivas. Se inicia la configuración del hecho generador mediante la ocurrencia de decisiones de la Administración en materia de clasificación del suelo (por ejemplo, rural a expansión), asignación de usos y edificabilidad, que constituyen normas generales, pero el hecho se concreta y produce de manera completa mediante la expedición de la licencia de urbanismo y/o construcción, que constituye la autorización específica. Con lo anterior se argumentó que el proceso de cálculo, liquidación y cobro de la participación en la plusvalía podía hacerse siempre y cuando el propietario o poseedor del inmueble no hubiera obtenido la licencia de urbanización o construcción.

De esta manera se desvirtuó el argumento alrededor de la posible retroactividad en el cobro de la participación, en el caso de que el Acuerdo se aprobara en 2002, 2003 o después, debido a que cualquiera de estas fechas sería posterior a 2000, año de adopción del POT. Siempre y cuando los propietarios de inmuebles en los que se hubiera empezado a configurar el hecho generador de plusvalía, mediante las normas generales del POT, de las UPZ y de los planes parciales, no hubieran obtenido las licencias mencionadas, habría lugar a todo el proceso por parte de la Administración Distrital para hacer el cobro de la participación.

ii) Especificó que para el caso del cálculo del efecto plusvalía por mayor aprovechamiento del suelo en edificación, si bien el método que quedó consignado en la Ley era equivocado, era posible recurrir a respaldos constitucionales y legales, con el fin de especificar que para este hecho generador debería utilizarse el método de avalúo residual; mediante este método se obtiene el precio del suelo como resultado de la incidencia o repercusión en éste, del número de metros cuadrados y/o del uso del suelo autorizados a construir:

... nos soportamos en el deber de asegurar el ejercicio del derecho de la colectividad a participar en las plusvalías derivadas de la acción urbanística del Estado, y en la obligación que tiene de aplicar el principio de equidad del sistema tributario para regular un tributo justo y equitativo, dentro de los límites de la Ley 388/97 y el artículo 338 de la Constitución Nacional, ... para ello se incluyó en el procedimiento para el cálculo del efecto plusvalía el elemento: “... la incidencia o repercusión sobre el suelo del número de metros cuadrados que se autoriza a construir ...". La precisión que se

\footnotetext{
${ }^{52}$ Para ayuda de los lectores se mencionan las tres mayores dificultades: i) El Acuerdo de Adopción de la Plusvalía en cualquier ciudad debería haberse aprobado con anterioridad o al tiempo de la aprobación del POT y ya no había sucedido de esta manera. Se consideraba que el POT contenía los hechos generadores. Esta circunstancia -no contar previamente con el Acuerdo- generaría un cobro de la participación con retroactividad, condición no admisible en términos tributarios; ii) la necesaria variación del método de cálculo del efecto plusvalía por mayor aprovechamiento del suelo en edificación, requería una modificación de la LDT, y iii) la generación de doble tributación con los impuestos predial y de renta.

${ }^{3}$ La explicación que se presenta no utiliza el rigor de los términos jurídicos y económicos contenidos en los conceptos que se elaboraron en su momento. Al hacer la exposición en términos que no son estrictamente técnicos, la intención es hacerlos de fácil comprensión para el lector.
} 
introduce consiste en hacer explícito lo que los avaluadores denominan precio de incidencia o repercusión... ${ }^{54}$.

El texto del Proyecto de Acuerdo desarrolló los temas que requerían alguna aclaración o precisión particular para el caso de Bogotá; es decir, evitó repetir el contenido del capítulo IX de la LDT, que, como se expuso, es bastante detallado y prolijo.

El texto aprobado tiene, en términos generales, el siguiente contenido ${ }^{55}$ :

- Objeto (art. 2): Establecer las condiciones generales para aplicar en Bogotá D.C. la participación en la plusvalía, de acuerdo con la Constitución Política y la LDT.

- Hechos generadores (art. 3): Especifica que los hechos generadores están constituidos por las autorizaciones específicas ${ }^{56}$ para destinar el inmueble a un uso más rentable o para incrementar el aprovechamiento del suelo en edificación. En el caso de Bogotá no se incluyó la incorporación de suelo rural a suelo de expansión porque el POT estableció que este cambio solo tendría efectos concretos mediante la aprobación de un plan parcial, que de hecho constituye la autorización de usos más rentables y un mayor aprovechamiento del suelo. Es decir, los dos hechos generadores establecidos incluyen la incorporación de suelo rural a de expansión.

La Administración Distrital decidió expresamente no incluir como hecho generador la ejecución de obras públicas, pues la Contribución de Valorización o por Mejoras tiene en Bogotá una tradición de uso y recuperación de costos de las obras bastante consolidada $^{57}$.

- Exigibilidad (art. 4): Especifica, en concordancia con la afirmación de que el hecho generador se concreta en la licencia, que el pago de la participación será exigible en el momento en que sea expedida la licencia y no antes.

- Determinación del efecto plusvalía (art. 5): Aclara que en el cálculo del efecto plusvalía "... se tendrá en cuenta la incidencia o repercusión sobre el suelo del número de metros cuadrados adicionales que se autoriza a construir, o del uso más rentable, aplicando el método residual"58.

- Este artículo contiene un parágrafo que, dando aplicación a que el hecho generador está constituido por la licencia y no por la norma general, determina que la Administración Distrital liquidará de manera general ${ }^{59}$, dentro de un período de tres meses a partir de que entre en vigencia el Acuerdo, la participación en la plusvalía a aquellos inmuebles en los que el POT o los instrumentos que lo desarrollen ${ }^{60}$ hayan dispuesto acciones urbanísticas, siempre y cuando no se haya configurado el hecho generador, es decir, no se haya expedido la licencia.

- El Acuerdo fue sancionado por el Alcalde el 30 de diciembre de 2003, con lo cual la

\footnotetext{
${ }^{54}$ Montaña, Magda Cristina, ex Subdirectora Jurídico Tributaria de la Secretaría de Hacienda Distrital.

${ }_{55}$ Solo se incluyen los temas contenidos en el Acuerdo que se consideran útiles para el objetivo del artículo; algunos son particularmente específicos y pueden confundir más que aclarar ideas o requieren una explicación extensa.

${ }^{56}$ El texto escrito de esta manera evidencia la superación de la interpretación que establecía que el hecho generador estaba constituido por la acción administrativa de asignar usos, edificabilidades o de incluir suelo rural como de expansión. Se precisa que el hecho generador es la autorización específica, que es la licencia de urbanización o construcción.

${ }^{57}$ La Administración prefirió no incluir este hecho generador y evitar un debate adicional a los que se pensaba iban a suceder. La Contribución de Valorización es una forma de recuperar la plusvalía y el término para su pago es de corto plazo, predecible en el tiempo.

${ }_{58}^{5}$ Con esta especificación se supera la imposibilidad del cálculo generada por el texto del artículo 77 de la LDT.

${ }^{59}$ Es decir, la Administración deberá solicitar los avalúos, revisar el cálculo y establecer el efecto plusvalía para cada uno de los inmuebles, según la zona geoeconómica homogénea.

${ }^{60}$ Por ejemplo, la reglamentación urbanística de las Unidades de Planeamiento Zonal UPZ y/o la adopción mediante decreto de los Planes Parciales.
} 
Administración tuvo plazo hasta el 30 de marzo de 2004 para cumplir con lo ordenado en el parágrafo del artículo $5^{\circ}$.

- Tarifa de la participación (art. 6): Se adoptó, dentro de los rangos establecidos por la Ley, una tarifa progresiva: 30\% para el año 2004, 40\% para el 2005 y 50\% de 2006 en adelante.

- Destinación de los recursos (art. 7): Dentro de las posibilidades de destinación de los recursos que estableció la LDT, el Acuerdo de Bogotá decidió que el $70 \%$ de todos los recursos se destinaran a alguna de las siguientes tres modalidades de oferta de vivienda de interés social: i) vivienda nueva o infraestructura y espacio público para estos proyectos de vivienda, ii) infraestructura urbana para zonas de mejoramiento integral y iii) programas de renovación urbana que incluyan viviendas de interés social. Un $15 \%$ para espacio público de la zona que genera la plusvalía ${ }^{61}$ y el $15 \%$ restante para compra de suelos clasificados como de protección y conservación ambiental y para estímulos, incentivos y compensaciones para inmuebles con tratamiento de conservación arquitectónica, histórica o cultural.

\section{Primera experiencia de aplicación de la participación en la plusvalía en Bogotá}

A mediados de enero de 2004 se inició el proceso para dar cumplimiento a lo establecido en el parágrafo del artículo 5 del Acuerdo 118 de 2003, sobre la responsabilidad de la Administración Distrital de liquidar el efecto plusvalía derivado de los instrumentos que ya hubieran especificado algunas de las decisiones generales del POT en materia de usos y edificabilidad, en un plazo de tres meses a partir del 30 de diciembre.

Para la fecha de expedición del Acuerdo se habían reglamentado 16 UPZ y adoptado 11 planes parciales, es decir, para estas áreas urbanas se habían especificado normas urbanísticas más precisas en su contenido que las del POT, pero todavía de carácter general, en el sentido de que si bien asignan usos y edificabilidades específicos y definidos para los inmuebles de un sector normativo, solamente cuando al propietario del inmueble se le otorgue la licencia respectiva, la norma será ya de carácter específico; dependerá del propietario hacer uso de las posibilidades que le otorga la norma, de forma total o parcial (ver plano 1: UPZ y planes parciales adoptados a diciembre de 2003).

En este proceso participaron funcionarios del Departamento Administrativo de Catastro Distrital, del Departamento Administrativo de Planeación Distrital y de la Secretaría de Hacienda; contó con la asesoría técnica y jurídica del Programa del LILP en Colombia y tuvo seguimiento cercano por parte de los directivos de las tres entidades.

Para el desarrollo de este proceso de liquidación del efecto plusvalía fue de mucha utilidad el procedimiento detallado que contiene la Ley en relación con la definición de plazos, actividades y responsables de ejecutar cada una de las etapas del proceso, desde la solicitud de cálculo del efecto plusvalía, hasta la inscripción del tributo en el folio de matrícula inmobiliaria. No fue necesario inventarse ningún procedimiento, sino actuar con cuidado y rigor en la aplicación de las indicaciones de la Ley, con el fin de evitar posteriores demandas en contra del proceso por parte de los todavía numerosos opositores a la medida.

A continuación se presenta una descripción sintética de los procedimientos básicos que desarrollaron de manera conjunta el DAPD, el DACD y la SHD para cumplir con la exigencia del Acuerdo.

\footnotetext{
${ }^{61}$ Esta fue una destinación que se introdujo en el texto del proyecto de Acuerdo, como resultado del debate político en el Concejo Distrital. Desde un punto de vista teórico, reduce el objetivo redistributivo que constituye componente esencial de la recuperación de la plusvalía.
} 


\subsection{Solicitud del DAPD al DACD, para que estimara el mayor valor por metro cuadrado o monto de la plusvalía}

Durante la primera semana del mes de febrero de 2004, la Directora del DAPD, mediante comunicación escrita, solicitó al Director del $D A C D^{62}$ determinar el efecto plusvalía para los sectores normativos de cada una de las 13 UPZ en los que el Decreto de adopción de la norma respectiva había hecho esta especificación, así como para un plan parcial.

La información enviada al DACD que acompañó la solicitud de cálculo del efecto plusvalía norma urbanística anterior, norma urbanística vigente, planos- garantizaba que los avaluadores tendrían la información necesaria para hacer los dos avalúos requeridos para establecer el efecto plusvalía. Los avaluadores debieron ser asesorados por un arquitecto de la Subdirección de Planeamiento Urbano del DAPD en la interpretación que debía darse a indicadores como los Índices de Ocupación y de Construcción, básicos para calcular la edificabilidad de los predios, y que con frecuencia están afectados en la norma por decisiones muy puntuales y excepciones sobre aislamientos laterales y posteriores de los edificios, voladizos o sobre las diversas formas de considerar los estacionamientos y los altillos ${ }^{63}$.

\subsection{Elaboración de los avalúos por parte del DACD}

En el DACD se vincularon al cálculo del efecto plusvalía tres oficinas distintas: i) la División de Actualización Catastral, responsable directa de la realización de los avalúos; ii) la Subdirección de Informática, a cuyo cargo está la base de datos predial de la ciudad ${ }^{64}$, y iii) la División de Cartografía, responsable del plano digital de la ciudad.

De las 13 UPZ reportadas por el DAPD para el cálculo de la plusvalía, una vez realizados los avalúos, el DACD confirmó que solamente en ocho de ellas se configuraba el efecto plusvalía $^{65}$. En estas ocho UPZ se generaba efecto plusvalía en aproximadamente 40 del total de sectores normativos, dentro de los cuales se contabilizaron cerca de 5.575 predios. Para determinarlo fue necesario realizar un total de 350 avalúos, utilizando el método de avalúos masivos, también denominado de zonas homogéneas geoeconómicas, en las que para un número superior a 250 inmuebles, pueden ser suficientes mínimo cinco puntos o avalúos de muestra ${ }^{66} 67$.

Aproximadamente cinco semanas después de que el DAPD solicitara la elaboración de los avalúos, es decir hacia mediados del mes de marzo, el DACD entregó al DAPD el informe técnico de la elaboración de los avalúos y del cálculo del efecto plusvalía para cada una de las UPZ.

\footnotetext{
${ }^{62}$ Bogotá decidió solicitar los avalúos al DACD, en lugar de hacerlo con avaluadores privados, otra de las posibilidades que establece la Ley.

33 El altillo lo constituye el último piso de un edificio, cuando no es un piso con entrada independiente, sino que corresponde al segundo piso interior de los apartamentos situados en la parte mas alta del edificio.

${ }^{64}$ Bogotá contaba para la época con aproximadamente 1.740 .000 predios urbanos.

${ }^{65}$ Esta situación se presentó debido a que los arquitectos del DAPD encargados de elaborar las normas de las UPZ asignaron, en algunas ocasiones, unas normas que si bien aparentemente implicaban un aumento de edificabilidad, debido a las condiciones particulares de los lotes y a las exigencias en materia de estacionamientos, hacían imposible la aplicación de la norma y, por lo tanto, la generación del efecto plusvalía.

${ }^{66}$ Para cada punto de muestra, de acuerdo con la metodología para calcular el efecto plusvalía, se debieron realizar dos avalúos. El primero debe simular que se aplica la norma de usos y edificabilidad anterior a la nueva que está autorizando la UPZ. El segundo debe simular que se aplica la nueva norma.

${ }^{67}$ La realización de los avalúos masivos, desvirtuó uno de los prejuicios que desestimulaba la aplicación del tributo: los altos costos de la elaboración de los avalúos. De acuerdo con este argumento, hubiera sido necesario hacer 5.575 avalúos, lo cual sí hubiera resultado muy costoso y hubiera vuelto muy complejo todo el procedimiento de cálculo, liquidación, notificación, registro en el folio de matrícula inmobiliaria, etc.
} 


\subsection{Liquidación de la participación en plusvalía, expedición de la resolución de determinación y notificación a propietarios y poseedores ${ }^{68}$}

Para dar cumplimiento a la ejecución de todo el proceso, hasta la publicación en periódicos de amplia circulación en la ciudad, el DAPD realizó los siguientes procesos:

- Revisión de los informes entregados por el DACD.

- Elaboración de un informe técnico para cada UPZ, en el que se consignó la revisión técnica realizada a los avalúos del DACD, se hizo la liquidación del efecto plusvalía y se aplicó la tasa de cobro.

- Elaboración de los reportes mediante los cuales se consignó, para cada zona homogénea geoeconómica y para cada uno de los inmuebles, el efecto plusvalía por $\mathrm{m}^{2}$ y se aplicaron las tasas de cobro.

- Elaboración de la resolución mediante la cual se determinó y se notificó a los propietarios y poseedores la liquidación de la participación en la plusvalía - publicación en ediciones dominicales de periódicos en el Distrito.

- Publicación de la Resolución en los periódicos La República, El Espectador y El Tiempo.

a) Revisión de los informes de cálculo del efecto plusvalía por parte del DAPD: Una vez recibidos los informes del DACD sobre la realización de los avalúos y el cálculo del efecto plusvalía, el DAPD tenía cinco días hábiles para objetar el cálculo en caso de ser necesario y solicitar su revisión al DACD. Con el fin de cumplir con este requisito, el DAPD organizó de manera muy rápida dos equipos de trabajo:

i) El primero integrado por los arquitectos que habían elaborado las normas urbanísticas de las 13 UPZ (Subdirección de Planeamiento Urbanístico). La tarea de cada uno de ellos fue revisar, en un plazo de dos días, si los avaluadores del DACD habían aplicado de manera correcta las normas urbanísticas con base en las cuales se hicieron los avalúos y se calculó la plusvalía. Esta revisión dio como resultado que en todos los sectores normativos se había hecho una correcta aplicación de la norma.

ii) El segundo, integrado por los economistas de la Subdirección Económica, de Competitividad e Innovación. Su responsabilidad fue, a partir del visto bueno de la Subdirección de Planeamiento en relación con la aplicación de la norma, revisar los avalúos hechos por el DACD. Para ello contaban con publicaciones especializadas y con un Observatorio del Mercado Inmobiliario que empezaba a constituirse en esa Subdirección. Como en el caso de la revisión de la norma, el informe de los avalúos también dio como resultado que éstos eran correctos; es decir, el DAPD no tuvo necesidad de solicitar al DACD la revisión de los mismos. b) Elaboración de un informe técnico para cada UPZ, en el que se consignó la revisión técnica realizada a los avalúos del DACD, se hizo la liquidación del efecto plusvalía y se aplicó la tasa de cobro: Con base en la anterior revisión, la coordinadora del proceso dentro del DAPD ${ }^{69}$ debió elaborar un informe para cada UPZ, en el que quedó consignado el proceso que condujo a la liquidación del efecto plusvalía para cada uno de los inmuebles objeto de la misma y a la aplicación de las tarifas correspondientes. La minuciosidad en la elaboración de todos los informes sobre el proceso de cálculo y liquidación de la plusvalía tuvo como objetivo, además

\footnotetext{
${ }^{68}$ Si bien los temas que están contenidos en este numeral constituyeron una responsabilidad técnica del DAPD, la SHD y la asesoría del LILP apoyaron la resolución de vacíos y dudas sobre la forma de desarrollar y resolver algunos de los procesos: i) liquidación de la participación en predios con efecto plusvalía mínimo, ii) contenido de informes técnicos, iii) texto de la resolución de determinación de la liquidación de la participación, entre otros.

${ }^{69}$ Arquitecta urbanista María Clara Vejarano, asesora de la Subdirección de Gestión Urbanística del DAPD y miembro del programa LILP - LAC.
} 
de dar respuesta a la exigencia del Acuerdo 118/2003, documentar y respaldar de manera detallada todo el proceso, previendo demandas contra el mismo, como efectivamente sucedió. Este informe, mediante el cual se dio cumplimiento a lo establecido en el parágrafo del artículo 5 del Acuerdo 118/2003, es decir, mediante el cual se liquidó el efecto plusvalía, fue suscrito por los subdirectores de Planeamiento Urbano, de Gestión Urbanística y Económica, de Competitividad e Innovación, y entregado a la Directora el 30 de marzo de 2004.

c) Elaboración de los reportes mediante los cuales se consignó, para cada zona homogénea geoeconómica y para cada uno de los inmuebles, la liquidación del efecto plusvalía por $\mathrm{m}^{2}$ y se aplicaron las tarifas correspondientes: Desde el 15 de marzo y de manera simultánea a la revisión y elaboración de informes a los que se acaba de hacer referencia, la Oficina Asesora de Sistemas del DAPD diseñó los cuadros de reporte de la liquidación del efecto plusvalía por $\mathrm{m}^{2}$ y de aplicación de las tarifas correspondientes para cada uno de los inmuebles, en cada una de las zonas homogéneas geoeconómicas, por UPZ y aplicó el programa de computador respectivo para producir los reportes necesarios. Este reporte se elaboró a partir de la base de datos de los 5.575 inmuebles que la Subdirección de Informática del DACD entregó al DAPD como parte del cálculo del efecto plusvalía. A manera de ejemplo, se incluye el encabezamiento de uno de los cuadros de reporte.

Unidad de Planeamiento Zonal No. 30, BOYACA REAL Decreto No. 70 de 02-06-2002

Tabla No. 1

Liquidación del efecto plusvalía por asignación de nuevas áreas de actividad con cambio de uso a uno más rentable, en relación con cada uno de los inmuebles objeto de la misma y aplicación de las tarifas correspondientes.

\begin{tabular}{|c|c|c|c|c|c|c|c|c|c|c|}
\hline \multicolumn{4}{|c|}{$\begin{array}{l}\text { Situación antes de la acción urbanística } \\
\text { generadora de plusvalía }\end{array}$} & \multicolumn{4}{|c|}{$\begin{array}{l}\text { Situación después de la acción urbanística } \\
\text { generadora de plusvalía }\end{array}$} & \multirow{2}{*}{\multicolumn{3}{|c|}{$\begin{array}{l}\text { Efecto plusvalía por m2 } \\
\text { de suelo \$261.050 } \\
\text { (pesos 2002) }\end{array}$}} \\
\hline \multicolumn{2}{|c|}{$\begin{array}{l}\text { Acuerdo } 6 \text { de } 1990 \text { y } \\
\text { decretos } \\
\text { reglamentarios de } \\
\text { normas de usos }\end{array}$} & \multicolumn{2}{|c|}{$\begin{array}{l}\text { Precio por m2 de } \\
\text { terreno \$ 238.950 } \\
\text { (pesos 2002) }\end{array}$} & \multicolumn{2}{|c|}{$\begin{array}{l}\text { Decreto No. } 348 \text { de } \\
08-15-2002 \\
\text { Normas de uso }\end{array}$} & \multicolumn{2}{|c|}{$\begin{array}{l}\text { Precio por } \mathrm{m} 2 \text { de } \\
\text { terreno \$ } \\
\text { (pesos año que sea }\end{array}$} & & & \\
\hline \multicolumn{11}{|c|}{ Zona homogénea física POT $6462215153121 \$ 500.000$} \\
\hline \multirow[b]{2}{*}{ Dirección } & \multirow{2}{*}{\multicolumn{2}{|c|}{ Chip }} & \multirow[b]{2}{*}{$\begin{array}{l}\text { Matrícula } \\
\text { Inmobiliaria }\end{array}$} & \multirow[b]{2}{*}{$\begin{array}{l}\text { Cédula } \\
\text { catastral }\end{array}$} & \multirow{2}{*}{\multicolumn{2}{|c|}{$\begin{array}{l}\text { Area terreno } \\
\mathrm{m} 2\end{array}$}} & \multirow{2}{*}{$\begin{array}{l}\text { Efecto } \\
\text { plusvalía } \\
\text { total predio }\end{array}$} & \multicolumn{3}{|c|}{ Tarifa por $\mathrm{m} 2$ de suelo $\$$} \\
\hline & & & & & & & & $\begin{array}{l}2004 \\
30 \%\end{array}$ & $\begin{array}{l}2005 \\
40 \%\end{array}$ & $\begin{array}{l}2004 \\
50 \%\end{array}$ \\
\hline $\mathrm{Cl} 709014$ & \multicolumn{2}{|c|}{ AAA0064CTK } & 1317964 & EGU79909 & 240.9 & & 62.886 .945 & 78315 & $\begin{array}{l}10442 \\
0\end{array}$ & $\begin{array}{r}13052 \\
6\end{array}$ \\
\hline $\begin{array}{l}\text { Siguen hacia } \\
\text { abajo, todos } \\
\text { los demás } \\
\text { predios de la } \\
\text { zona homogé } \\
\text { nea } \\
\text { geoeconó } \\
\text { mica. }\end{array}$ & & & & & & & & & & \\
\hline
\end{tabular}

Estos cuadros de reporte hicieron parte de la liquidación del efecto plusvalía, producida mediante los informes que los subdirectores entregaron a la Dirección del DAPD el 30 de marzo, así como de la publicación en tres ediciones dominicales en periódicos de amplia circulación en Bogotá D.C.

d) Elaboración de la Resolución mediante la cual se determinó y se notificó a los propietarios y poseedores la liquidación de la participación en la plusvalía - publicación en ediciones dominicales de periódicos en el Distrito: Inmediatamente después del 30 de marzo, el DAPD y la SHD iniciaron la elaboración del acto administrativo (Resolución) mediante el cual se 
determinó el efecto plusvalía, de acuerdo con los plazos establecidos por la LDT ${ }^{70}$.

La Resolución No. 0220 fue adoptada por la Directora del DAPD el 22 de abril de 2004, "por medio de la cual se liquida el efecto plusvalía causado en relación con cada uno de los inmuebles localizados en las zonas o subzonas objeto de dicha participación, correspondientes a las UPZ Nos. 19, 29, 30, 39, 44, 88/97, 102, 07 y al Plan Parcial de la Magdalena, y se determina el monto de la participación en plusvalía de conformidad con las tarifas aprobadas por el Concejo Distrital".

El 25 de abril, domingo siguiente a la expedición de la Resolución, se hizo la primera publicación de la misma y de los reportes con la información para cada uno de los predios en el periódico La República. El 2 de mayo se publicó en el periódico El Espectador y el 9 de mayo en El Tiempo. De esta manera se completó el proceso de cálculo, liquidación, determinación y notificación a propietarios y poseedores de la participación en la plusvalía.

Otro de los argumentos que han planteado personas y funcionarios opuestos a la aplicación del tributo, es el relacionado con el costo que implica su puesta en marcha. En el caso de Bogotá, la realización de los aproximadamente 350 avalúos tuvo un costo aproximado de US\$ 27.300. La publicación de la Resolución 0220 de 2004 y de los listados con los 5.575 inmuebles en los tres diarios fue del orden de US\$57.000. Es decir, el costo total de los dos procedimientos para los cuales la Administración debió hacer un pago fue de US\$84.300. EI recaudo de la participación hasta marzo de 2006 se aproximaba a los US $\$ 9.850 .000^{71}$. Las cifras concretas son el mejor argumento para desestimar la apreciación de que puede ser más costoso hacer el cobro, que lo que se obtendrá por el recaudo ${ }^{72}$.

\subsection{Elaboración de Decreto Reglamentario del Acuerdo 118 de 2003}

Mientras que el DAPD y el DACD desarrollaban los procesos técnicos de cálculo y liquidación de la participación en la plusvalía, la SHD, con la asesoría del LILP, desarrolló y clarificó los aspectos de técnica tributaria y jurídica necesarios para respaldar todo el proceso.

Como resultado de este trabajo, el 29 de marzo de 2004, el alcalde mayor de la ciudad, Luis Eduardo Garzón, la directora del DAPD, Carmenza Saldías, y el secretario de Hacienda Distrital, Pedro Rodríguez, adoptaron el Decreto No. 084 -reglamentario del Acuerdo 118-, "por el cual se definen los lineamientos para regular la operatividad de la liquidación del efecto plusvalía y la determinación privada de la participación en plusvalía".

El contenido de este Decreto establece decisiones sobre la organización y competencias institucionales frente al proceso de determinación del efecto plusvalía, cálculo del mismo, control y administración del tributo, en relación con procesos específicos como ${ }^{73}$ :

- Procesos de liquidación del efecto plusvalía, a cargo del DAPD.

- Estimación general del efecto plusvalía: Autoriza a que sin perjuicio de la responsabilidad que tienen el DACD, el IGAC o peritos privados para establecer el mayor valor por metro cuadrado de suelo, el DAPD podrá establecer una estimación general del efecto plusvalía en los decretos mediante los cuales se expiden normas urbanísticas para UPZ, planes parciales y

\footnotetext{
${ }^{70}$ De acuerdo con el artículo 81 de la Ley, la Administración dispone de 30 días hábiles -después de tener la liquidación de la participación en la plusvalía- para expedir la Resolución que la determina.

${ }^{71}$ Son cifras aproximadas, pues el recaudo no corresponde exclusivamente a los predios para los cuales se hizo la liquidación en marzo de 2003. En la medida en que el procedimiento se ha vuelto rutinario para la Administración, el recaudo de aproximadamente US\$4.500.000 del total recaudado, incluye pagos hechos por inmuebles a los que se les hizo la liquidación después de marzo de 2003.

${ }^{72}$ Es necesario hacer la aclaración de que si los municipios acuden para la elaboración de los avalúos a las lonjas de propiedad raíz, es decir, a avaluadores privados, los costos no son sustancialmente mayores. Esto ya se evidenció en el caso de la ciudad de Pereira, en la elaboración de avalúos para la Operación Urbanística Ciudadela Gonzalo Vallejo Restrepo.

${ }_{73}$ En la LDT, estos procesos están asignados de manera genérica a la Administración Municipal, es decir, al alcalde. En el momento de dar aplicación concreta al tributo, se hace evidente que no será el alcalde quien deba asumir estas responsabilidades, sino los directores de las entidades directamente concernidas.
} 
otros instrumentos de planeamiento ${ }^{74}$.

- Inscripción de la liquidación en el registro público de inmuebles o historial de transferencia del dominio: Establece que para fines de publicidad ante terceros, el DAPD ordenará a la Oficina de Registro de Instrumentos Públicos se haga esta inscripción una vez esté en firme la resolución de liquidación del efecto plusvalía.

- Adopción de un mecanismo de pago anticipado del tributo -declaración de autorretención o determinación privada de la participación en plusvalía-, en tanto se expide la liquidación definitiva del efecto plusvalía. Para esta declaración de autorretención, el contribuyente utilizará como base para determinarla, la estimación general hecha por el DAPD en los decretos de adopción de normas.

\subsection{Continuación del proceso de puesta en marcha de la participación en la plusvalía - Avances}

Como continuación del proceso de puesta en marcha de la participación en la plusvalía en Colombia durante el año 2004, se hará referencia a dos escenarios en los que continuaron desarrollándose iniciativas: a) Ministerio de Ambiente, Vivienda y Desarrollo Territorial y b) la misma ciudad de Bogotá.

a) Ministerio de Ambiente, Vivienda y Desarrollo Territorial: Los avances logrados por Bogotá mediante la adopción del Acuerdo 118 de 2003, en relación con algunos de los obstáculos que se habían identificado para la aplicación de la participación en la plusvalía, tuvieron un efecto muy importante en el Gobierno Nacional.

El 3 de junio de 2004, el Presidente de la República y los ministros de Ambiente, Vivienda y Desarrollo Territorial y de Hacienda y Crédito Público adoptaron el Decreto Nacional No. 1788, "Por el cual se reglamentan parcialmente las disposiciones referentes a la participación en plusvalía de que trata la Ley 388 de 1997". En este Decreto se logró la confirmación de algunas de las regulaciones del Acuerdo de Bogotá, con lo cual se dio un importante soporte a este Acuerdo y se allanó el camino para los demás municipios del país ${ }^{75}$.

Entre los temas de la experiencia de Bogotá que se puede considerar que tuvieron influencia en el contenido del Decreto Nacional, se encuentran los siguientes:

i) Adopción, para el cálculo del efecto plusvalía por mayor aprovechamiento del suelo en edificación, de la aclaración de que se tendrá en cuenta "la incidencia de la edificabilidad adicional autorizada sobre el valor del suelo". De esta manera se adoptó la medida que había sido utilizada en el artículo 5 del Acuerdo 118.

ii) Exigencia del pago de la participación en la plusvalía, en el momento en que vaya a ser expedida la licencia de urbanización o construcción al interesado y no en el momento de solicitar la licencia, como establecía el anterior Decreto Reglamentario de Plusvalía. De esta manera se ratifica el concepto de que la autorización específica (licencia) es el hecho generador de la plusvalía ${ }^{76}$.

b) Bogotá: Las entidades distritales involucradas en la puesta en marcha de la participación en la plusvalía -DACD, DAPD y SHD- continuaron con procesos de capacitación de los

\footnotetext{
${ }^{74}$ Esta medida hace parte de la posibilidad de que el contribuyente haga una declaración del tributo -declaración de autorretención- en el momento en que se le expida la licencia de urbanismo o construcción, si aún no ha quedado en firme la liquidación y aplicación de tarifas del tributo por parte de la Administración Distrital. Es un procedimiento tributario para impedir la evasión en el pago, debido a la asincronía entre el proceso de otorgamiento de la licencia de urbanización o construcción y el proceso de la liquidación de la participación en plusvalía.

${ }^{75}$ La influencia de Bogotá en el Gobierno Nacional, se logró mediante la participación en las discusiones que se daban en los ministerios, del Secretario de Hacienda Distrital, Israel Fainboim, quien, además de su comprensión del tema, había aceptado y compartido la asesoría del LILP.

${ }^{76}$ Se da respaldo al argumento desarrollado por Bogotá acerca de que la generación del efecto plusvalía es un acto complejo, que se construye sucesivamente, pero que sólo se concreta y concluye en el momento de otorgamiento de la licencia de urbanización y construcción.
} 
funcionarios a la nueva responsabilidad y con la precisión de procedimientos internos en cada entidad ${ }^{77}$.

El mayor esfuerzo de definición y adaptación a nuevas rutinas lo debió realizar la SHD. Después de que el DAPD publicó la Resolución de Liquidación de la Participación en la Plusvalía, era necesario precisar los procedimientos de pago por parte de los contribuyentes, tarea específica de la SHD.

- Entre los temas en los que la SHD logró hacer avances, se encuentran los siguientes:

i) Hacer comprensivo el tema para todos los funcionarios, debido a que es un tributo cuya finalidad tiene horizontes urbanos más complejos que los de cualquier otro tributo, lo cual requiere que los funcionarios encargados del control y orientación al ciudadano sean concientes del contenido social y colectivo del tributo. Por ello se decidió capacitar a los funcionarios en los conceptos básicos del mecanismo de recuperación de plusvalías, como un instrumento de gestión del suelo.

ii) Atender y prestar servicio al ciudadano que solicita licencias de urbanismo o construcción sobre inmuebles beneficiados con aprovechamientos que generan el pago del tributo de la participación en plusvalía, en particular en la asesoría para el diligenciamiento del formulario de declaración privada de la liquidación de la participación en plusvalía, que debe hacer el particular con el fin de obtener la licencia.

iii) Responder las solicitudes de certificación para autorizar a los particulares a realizar cambios en el registro del historial de propiedad sobre los bienes inmuebles en los cuales aparece publicado el acto de liquidación del efecto plusvalía. Este procedimiento implica revisar si se ha expedido la licencia de urbanismo o construcción y, por lo tanto, para autorizar la eliminación de la inscripción del acto de liquidación del efecto plusvalía, debe exigirse la declaración privada del impuesto que se debe pagar y la constancia del pago del tributo. De no haber ocurrido la autorización específica (licencia), la Secretaría de Hacienda debe autorizar el registro del cambio de propietario, por cuanto aún no se ha generado la exigibilidad del cobro de la participación.

iv) Especificar formas y facilidades para el pago del tributo en dinero en efectivo ${ }^{78}$, como el otorgamiento de plazos, antes de iniciar procesos de cobro. De esta manera se autoriza obtener la licencia de urbanización o construcción, acreditando como mínimo el pago del 30\% del total de la deuda y garantizando el cumplimiento de la obligación restante, mediante garantías a través de pólizas de seguro o prenda sobre bienes muebles o hipoteca sobre inmuebles.

v) Coordinar con los curadores urbanos ${ }^{79}$, la metodología para informar a la SHD sobre el otorgamiento de licencias en las cuales hayan autorizado mayor aprovechamiento o cambio de uso en virtud del nuevo Plan de Ordenamiento Territorial, para verificar si ha cumplido correctamente la obligación de declarar y pagar (control tributario) y, a su vez, certificar a las oficinas de registro inmobiliario.

vi) Conformar, conjuntamente con el DAPD, una base de datos de los predios a los que se ha hecho la liquidación o la preliquidación ${ }^{80}$ de la participación para posteriores controles.

- $\quad$ Por su parte, en el DAPD se conformó un equipo de funcionarios de las diversas subdirecciones, Grupo de Plusvalías, con el fin de que asuma la función de realizar de manera rutinaria las diversas etapas que son responsabilidad del DAPD y garantice que la Dirección

\footnotetext{
${ }^{77}$ En este aparte del artículo se consignan los avances de cada entidad hasta septiembre de 2005. Es posible que con posterioridad a esta fecha, haya habido nuevos desarrollos que no se incluyen.

${ }_{78}^{78}$ Aún no se ha avanzado en la definición y reglamentación de las otras formas de pago autorizadas por la Ley.

${ }_{79}$ Personas particulares en quienes la LDT delegó la función pública de expedir las licencias de urbanización y construcción, en los municipios colombianos de más de 100.000 habitantes.

${ }^{80}$ Preliquidación es otro nombre para designar lo establecido en el Decreto Reglamentario del Acuerdo 118/2003, en relación con la posibilidad de que el DAPD realice una estimación general del efecto plusvalía dentro del proceso de trámite de expedición de planes parciales, UPZ u otros instrumentos de planeamiento.
} 
del DAPD cumpla con los trámites necesarios en los tiempos establecidos: i) elaboración de liquidaciones generales del efecto plusvalía durante la expedición de reglamentaciones de planes parciales, UPZ y otros instrumentos de planeamiento; ii) solicitud de cálculo del efecto plusvalía al DACD; iii) revisión, visto bueno y liquidación del efecto plusvalía y de la participación; iv) elaboración de Resolución que la determina; v) publicación en periódicos, entre otros procedimientos.

- $\quad$ En el DACD no ha sido necesario hacer adecuaciones particulares, ni trabajo específico con los funcionarios. Esta entidad tiene la capacidad de responder a las exigencias de la elaboración de los avalúos y del cálculo del efecto plusvalía, con su estructura institucional y su funcionamiento corriente.

- De manera conjunta, entre el DAPD y la SHD se avanzó en otro dos frentes de trabajo: i) Coordinación con la Oficina de Registro de Instrumentos Públicos, para la publicación en el registro del historial de los inmuebles ${ }^{81}$ del acto de liquidación del efecto plusvalía y para la comunicación que se debe establecer con la SHD, con el fin de actualizar la inscripción y verificar el cumplimiento del pago del tributo ${ }^{82}$. De manera general, la instrucción administrativa hace referencia a los siguientes temas:

.ii) Respuestas a demandas judiciales contra el Acuerdo 118 de 2003 y los actos de liquidación: se ha avanzado con solidez en la defensa judicial contra el Acuerdo 118 de 2003. Tal como se previó, cuando la ciudad comprendió que el cobro del tributo era una realidad, se iniciaron las demandas en su contra. Los argumentos que se prepararon para defender la presentación del Proyecto de Acuerdo en el Concejo han sido los principales argumentos para responder a las demandas. Se considera que la defensa del tributo ya está estructurada.

\section{Conclusiones}

La experiencia de Bogotá en relación con la aprobación del Acuerdo que reglamenta la recuperación de la plusvalía, así como la ejecución del primer procedimiento de cálculo del efecto plusvalía, liquidación, notificación y cobro de la participación, se puede considerar sin duda alguna como un importante logro de la Administración Distrital, una experiencia exitosa. Los factores que contribuyeron al buen resultado de esta experiencia son de diverso orden. Algunos están relacionados con condiciones muy específicas de Colombia, que no son fácilmente reproducibles de manera literal en otros países, aun cuando tampoco constituyen condiciones insustituibles. Otros aspectos que contribuyeron al éxito de la experiencia están relacionados con actividades y procedimientos corrientes y cotidianos del normal desarrollo de las entidades públicas y con el desempeño oportuno y responsable de los funcionarios de estas entidades.

Entre las condiciones que se presentaron en Bogotá y que pueden considerarse como derivadas de las muy particulares circunstancias de Colombia y de la ciudad se encuentran las siguientes:

- La referencia expresa de la Constitución Política de Colombia a que las entidades públicas deben participar en la plusvalía que genere su acción urbanística, participación que es calificada por la Constitución como un derecho colectivo y del ambiente. Se puede decir, por lo tanto, que en Colombia la recuperación de la plusvalía es un mandato constitucional, lo cual otorga una clara legitimidad y vigor a su recuperación para la colectividad. Si bien esta circunstancia constituyó un muy importante y eficiente respaldo al proceso de aprobación del Acuerdo mediante el cual la ciudad de Bogotá adoptó la recuperación de la plusvalía como un tributo que debía ser cobrado en la ciudad, no quiere decir que la consideración de la plusvalía como un derecho constitucional sea condición indispensable y necesaria para que en otros países de América Latina sea posible la puesta en marcha

\footnotetext{
${ }^{81}$ El registro historial de los inmuebles es responsabilidad de esta oficina.

${ }^{82}$ Según lo establecido en el artículo 81 de la LDT.
} 
de este tributo. Numerosos juristas latinoamericanos del derecho urbano coinciden en afirmar que con la actual estructura, principios y contenidos jurídicos de las legislaciones de los países de América Latina es perfectamente posible su implementación.

- La referencia explícita que la Ley de Desarrollo Territorial hace en relación con la participación en la plusvalía, así como el detallado procedimiento que establece para hacer operativa su implementación. De manera similar al papel que ha cumplido la Constitución Política, la consideración de la participación en la plusvalía en la Ley de Desarrollo Territorial constituyó un valioso respaldo al proceso de adopción del tributo en Bogotá. Sin duda, el amplio detalle que contiene la Ley fue una condición definitiva para que en Bogotá, dentro de un límite de tiempo bastante estrecho, se pudiera hacer el primer cobro de la participación. Si bien un número reducido de países en América Latina dispone en la actualidad del respaldo legislativo requerido, se observa una tendencia reciente a adoptar legislaciones urbanísticas más progresistas y modernas en varios países de la región (Brasil, Colombia, Panamá, Uruguay, por mencionar solamente algunos), circunstancia que sin duda debe ser aprovechada para incluir la redistribución social de la plusvalía.

- La inequívoca y explícita actitud favorable y de respaldo político expresada por el Alcalde de la ciudad, que se hizo evidente en su exigencia a las entidades distritales interesadas en el desarrollo urbano de que elaboraran el proyecto de acuerdo de adopción de la participación en la plusvalía para su presentación y debate en el Concejo Distrital. El comportamiento del Alcalde de la ciudad es expresión de un número creciente de alcaldes de ciudades latinoamericanas que son electos por votación directa de los ciudadanos, mediante procesos políticos reconocidos como "voto de opinión". El sufragio de los votantes expresa coincidencia e identificación con las propuestas políticas de un candidato y su comportamiento electoral se deslinda de las indeseables prácticas clientelistas y populistas. Antanas Mockus, como candidato, estableció en su campaña a la Alcaldía de Bogotá que incrementaría los impuestos de la ciudad, anuncio que desde el punto de vista político resultaba sorprendente, pues propiciaba una situación en la que sus posibles electores podrían sentirse desmotivados a darle su apoyo. Su actitud fue políticamente responsable, aun a riesgo de que su propuesta le resultara perjudicial, desde el punto de vista de la votación. Si bien el alcalde Mockus no era una persona especializada en aspectos específicamente urbanísticos y tributarios, entendió la importancia de que el Distrito adoptara la participación en la plusvalía y dio total respaldo e impulso a la elaboración del proyecto de acuerdo y a su presentación en el Concejo Distrital.

De manera consistente y coherente con su explícito apoyo a la puesta en marcha de la participación en la plusvalía, dio instrucciones muy concretas a los directores de las entidades públicas de la ciudad que debían involucrarse en el proceso (Departamento Administrativo de Planeación, Departamento Administrativo de Catastro y Secretaría de Hacienda), para que comprometieran todos los esfuerzos de la entidad en lograr que la medida fuera ejecutada de manera oportuna y eficiente, instrucción que permitió hacer un trabajo muy coordinado entre las diversas entidades.

Entre los factores que contribuyeron a la buena realización de esta experiencia, y que no están tan asociados a circunstancias específicas de Colombia y Bogotá, deben mencionarse:

- La puesta en marcha de un proceso de preparación e inducción previo a la presentación del proyecto de acuerdo de aprobación de la participación en la plusvalía en el Concejo Distrital, que involucró a algunos funcionarios de las entidades responsables ya mencionadas (Planeación, Catastro y Secretaría de Hacienda) y a los miembros del Concejo Distrital, particularmente a los concejales ponentes del proyecto de Acuerdo, es decir a los que tuvieron la responsabilidad de presentar y dirigir la discusión del proyecto de acuerdo ante el pleno del Concejo. Como las entidades que presentaron el proyecto de Acuerdo al Concejo Distrital (Planeación y Secretaría de Hacienda) conocían del posible 
ambiente contrario a la adopción de la plusvalía por parte de los concejales de la ciudad, la inducción previa se concentró en argumentar y explicar acerca de la legitimidad y beneficios de la participación en la plusvalía, desde el punto de vista de la equidad y la eficiencia del mercado del suelo y de las ventajas desde el punto de vista tributario.

- La discusión y concertación, previa a la presentación del proyecto de Acuerdo, con los gremios inmobiliarios de la ciudad, a fin de contar con su adhesión, que se consideraba necesaria por cuanto son agentes con una fuerte capacidad de incidencia y presión, y cuyos intereses gremiales están fuertemente representados en el Concejo Distrital. Esta concertación con los gremios inmobiliarios dio por resultado que uno de los gremios con mayor incidencia manifestara de manera clara y concreta su apoyo, con lo cual se facilitó la labor de discusión en el Concejo Distrital.

- Elaboración de un concepto jurídico por parte de un abogado con amplio reconocimiento en temas tributarios, en el cual se argumentó acerca de la legitimidad y oportunidad de la adopción de la participación en la plusvalía en las ciudades colombianas, con énfasis en algunos aspectos específicos tanto conceptuales como procedimentales, que permitieron que las entidades distritales responsables de la discusión del proyecto de acuerdo en el Concejo tuvieran argumentos y defensas suficientemente bien elaboradas desde el punto de vista conceptual, técnico y jurídico.

- El alto nivel técnico de los funcionarios del Departamento de Planeación, de Catastro y de la Secretaría de Hacienda, quienes asumieron sus respectivas responsabilidades de manera muy seria y eficiente. No todos los temas técnicos estaban adecuadamente resueltos y planteados; por ejemplo, el contenido de las normas urbanísticas y arquitectónicas correspondientes a la situación anterior al POT y las correspondientes al POT, con base en las cuales se hacen los avalúos para el cálculo del efecto plusvalía, evidenció una carencia de conocimiento sobre el comportamiento del mercado del suelo y aun de las características de los procesos inmobiliarios, por parte de quienes fueron responsables de elaborarlas. De esta manera, sobre una presunción inicial de que los predios generadores de plusvalía de esta primera experiencia se acercaban a 18.000, se constató que, debido a insuficiente elaboración de las normas, solamente el $31 \%$ de este número de predios resultó ser generador de efecto plusvalía. Pero, en términos generales, el trabajo técnico de los funcionarios se caracterizó por su compromiso, rigor y eficiencia.

De esta manera se ha presentado la experiencia de aprobación del acuerdo de adopción de la participación en la plusvalía en la ciudad de Bogotá y se ha hecho un seguimiento al proceso que permitió que desde un ambiente pesimista y contrario a la adopción de la plusvalía, se pasara a una realidad concreta muy favorable, sin embargo no exenta aún de dificultades y de intentos por echar atrás la medida. A partir de la decisión y experiencia de Bogotá, aproximadamente 25 municipios colombianos, entre ciudades grandes, intermedias y pequeñas, han adoptado sus propios acuerdos de adopción de la participación en la plusvalía $^{83}$.

\footnotetext{
${ }^{83}$ Al momento de finalizar la adaptación de este artículo para la revista ACE, mayo de 2008, han sucedido cambios importantes y no necesariamente de buen signo, a juicio de la autora del artículo, en la puesta en funcionamiento de la participación en plusvalías en Bogotá. El análisis y evaluación de estos cambios merece una investigación específica, que no alcanza a ser consignada en el presente artículo.
} 


\section{Bibliografía.}

García Bellido, Javier (1998). Perspectivas del nuevo urbanismo colombiano: un análisis de su estructura. En: Desarrollo Urbano en cifras. Bogotá - Colombia No. 5, agosto 1998.

Viceministerio de Vivienda, Desarrollo Urbano y Agua Potable - Cenac.

Gravagnuolo, Benedetto (1998). Historia del urbanismo en Europa 1750 - 1960. Ediciones Akal, S.A. 1998. Madrid - España

Jaramillo, Samuel (1998). Consideraciones teóricas sobre la participación de los municipios en las plusvalías urbanas. En: Desarrollo urbano en cifras. Bogotá - Colombia No.4, mayo 1998. Viceministerio de Vivienda, Desarrollo Urbano y Agua Potable - Cenac.

Jaramillo, Samuel (2001). La experiencia colombiana en la recuperación estatal de los incrementos del precio del suelo. La Contribución de Valorización y la Participación en Plusvalías. En: Recuperación de plusvalías en América Latina, alternativas para el desarrollo urbano. Smolka, Martim y Furtado, Fernanda, editores. Pontifica Universidad Católica de Chile, Eurelibros, Lincoln Institute of Land Policy.

Le Corbusier. Principios de Urbanismo (La Carta de Atenas). Editorial Ariel, S.A. Barcelona, 1989

Maldonado, María Mercedes. La propiedad en la Constitución colombiana de 1991. Superando la tradición del código civil. Versión ajustada para el Curso profesional de recuperación en plusvalías en América Latina, Lincoln Institute of Land Policy, Septiembre 2003 y 2004, de la publicada en Arocha, Jaime., compilador. 2004. Utopía para los excluidos. El multiculturalismo en África y América Latina. Bogotá: Universidad Nacional de Colombia, Facultad de Ciencias Humanas, Centro de Estudios Sociales CES, pp. 347-363.

Mancuso, Franco. Las experiencias del zoning. Editorial Gustavo Gili, S.A. Barcelona, 1980.

Mumford, Eric (2000). The CIAM discourse on Urbanism, 1928 - 1960. The MIT Press. Cambrisge, Massachusetts - London, England. 2000

Rossi, Aldo (1982). La arquitectura de la ciudad. Editorial Gustavo Gili, S.A. Barcelona, 1982

Smolka, Martim y Furtado, Fernanda (2001). Ensayo introductorio: Recuperación de plusvalías en Latinoamérica: ¿bravura o bravata?. En: Recuperación de plusvalías en América Latina, alternativas para el desarrollo urbano. Smolka, Martim y Furtado, Fernanda, editores. Pontificia Universidad Católica de Chile, Eurelibros, Lincoln Institute of Land Policy. 2001

Vejarano, María Clara (2005). Contribución de valorización. La experiencia de Bogotá durante la década de los 80 y 90. Lincoln Institute of Land Policy. Sin publicar

Vejarano, María Clara compiladora - editora (2007). Movilización social de la valorización de la tierra: casos latinoamericanos. Lincoln Institute of Land Policy Cambridge, Massachussets. CD Rom. 